\title{
unasa Im-85738
}

NASA Technical Memorandum 85738

NASA-TM-85738 19840007133

ANALYSIS OF INTERLAMINAR STRESSES IN THICK

COMPOSITE LAMINATES WITH AND WITHOUT EDGE

DELAMINATION

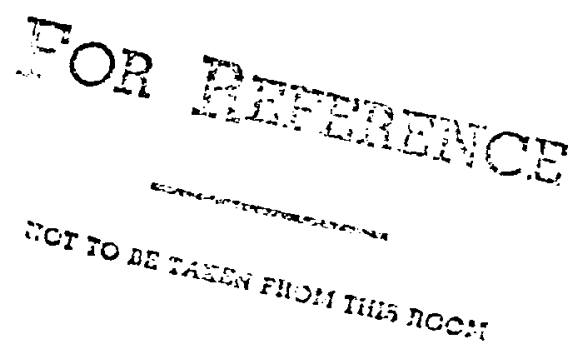

John D. Whitcomb and I, S, Raju

JANUARY 1984

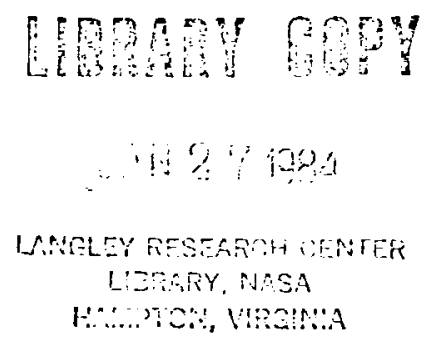


The effect of laminate thickness on the interlaminar stresses in rectangular quasi-isotropic laminates under uniform axial strain was studied. Laminates from 8-ply to infinitely thick were analyzed. Thick laminates were synthesized by stacking $(45 / 0 /-45 / 90)$ ply groups, rather than grouping like plies. Laminates with and without delaminations were studied.

In laminates without delaminations, the free-edge interlaminar normal stress distribution in the outer ply groups was insensitive to total laminate thickness. The interlaminar normal stress distribution for the interior ply groups was nearly the same as for an infinitely thick laminate. In contrast, the free-edge interlaminar shear stress distribution was nearly the same for inner and outer ply groups and was insensitive to laminate thickness. In laminates with delaminations, those delaminations near the top and bottom surfaces of a thick laminate have much larger total strain-energy-release rates $\left(G_{T}\right)$ and mode I-to-total $\left(G_{I} / G_{T}\right)$ ratios than delaminations deep in the interior. Therefore, delaminations can be expected to grow more easily near the surfaces of a laminate than in the interior. This is consistent with experimental results reported in the literature. Also, near surface delaminations in thin laminates tend to have larger strain-energy release rates than corresponding near surface delaminations in thick laminates.

\section{INTRODUCTION}

Interlaminar stresses develop at free edges and delamination fronts in composite laminates loaded in-plane because the individual anisotropic plies have different mechanical and thermal properties. In particular, differences in Poisson's ratios, shear-extension coupling coefficients, 
and thermal expansion coefficients cause each ply to try to deform differently. Compatibility of ply deformations is enforced by interlaminar stresses near free edges and delamination fronts.

Interlaminar stresses have been studied extensively for thin laminates, e.g. 4- and 8-ply laminates. But most practical laminates, especially those for compression structures, consist of considerably more than eight plies. A few studies of thicker laminates (refs, 1-2) have found that thicker laminates are more prone to delaminate than thinner laminates of the same stacking sequence; that is, a $\left[0_{2} / 45_{2} /-45_{2} / 90_{2}\right]_{s}$ laminate will delaminate at a lower strain level than a $[0 / 45 /-45 / 90]_{s}$ laminate. But like plies need not be grouped together in thick laminates. If like plies are not grouped together, are thicker laminates more or less prone to delaminate than thinner laminates? References 3 and 4 report results for related laminates in which the thinner laminate delaminates, but not the thicker one. The objective of this paper is to analytically determine the effect of laminate thickness on interlaminar stresses in rectangular quasi-isotropic laminates of different thicknesses under mechanical loading. Laminate thicknesses from 8-ply to infinitely thick were considered. Laminate thickness was varied by changing the number of plies instead of changing the ply thickness. For laminates without delamination, the free-edge interlaminar stresses were examined through the laminate thickness and across the laminate width. Quasi-threedimensional (Q3D) finite element analysis was used to calculate stresses. Interlaminar stresses near delamination fronts in delaminated specimens were characterized in terms of strain-energy-release rates. Strainenergy-release rates were calculated two ways: with a Q3D finite element analysis and with a classical laminate theory (CLT) analysis. The results 


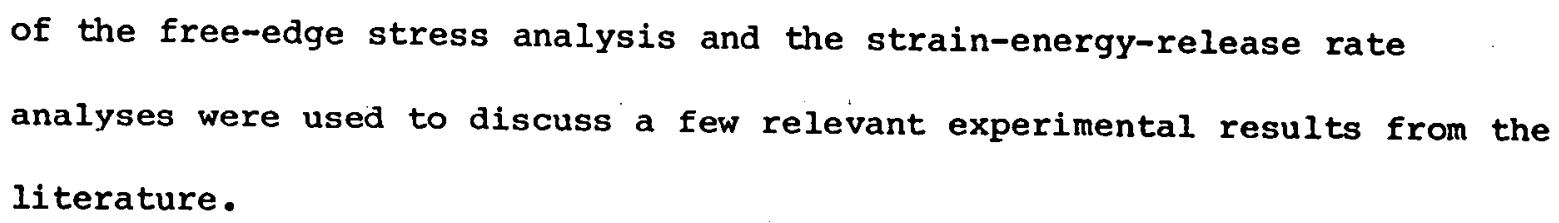

\section{NOMENCLATURE}

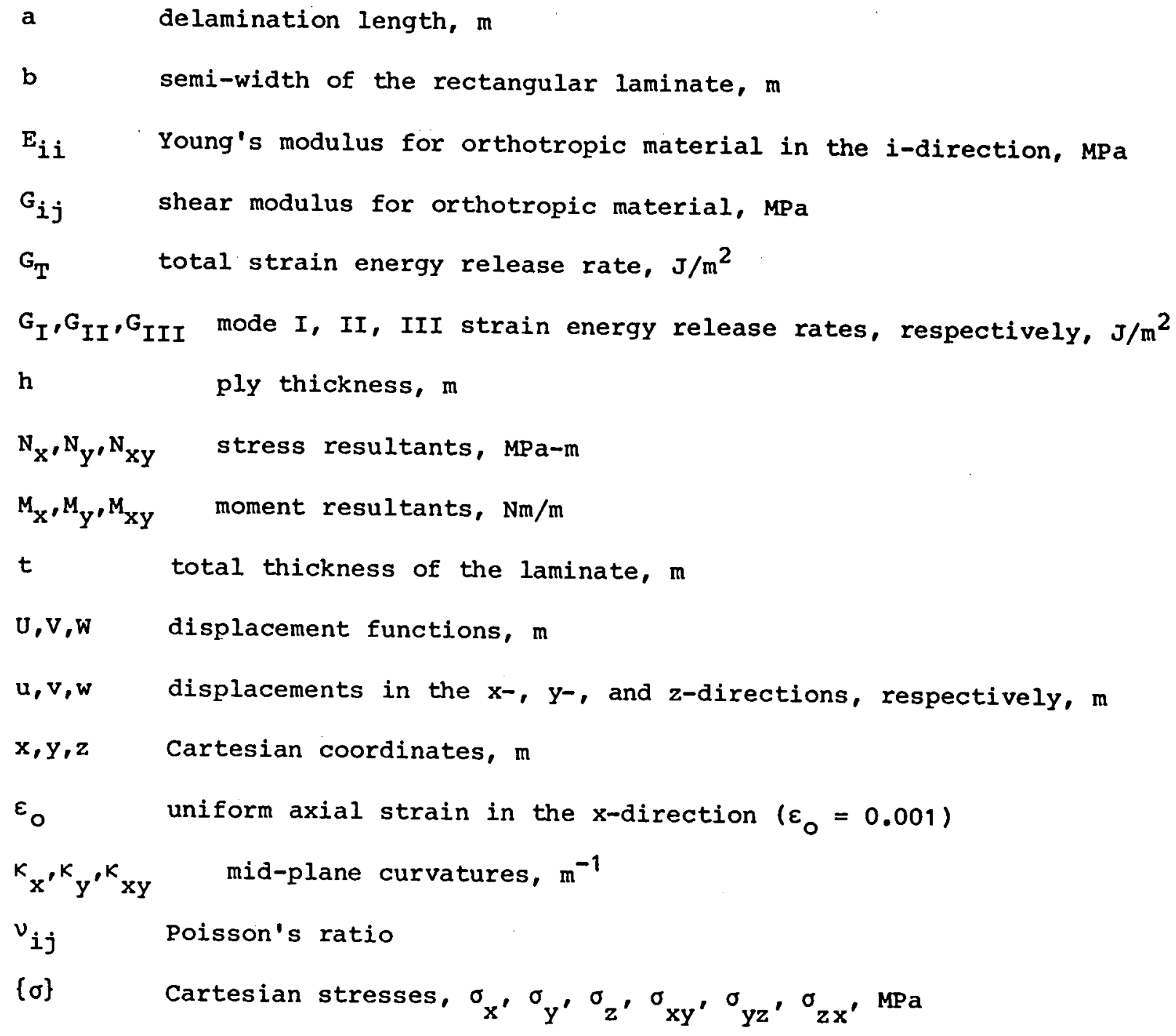


Others

$$
\begin{array}{ll}
{\left[(45 / 0 /-45 / 90){ }_{s}\right]_{n}} & \begin{array}{l}
(45 / 0 /-45 / 90 / 90 /-45 / 0 / 45) \\
\text { repeated } n \text { times a repeating unit }
\end{array} \\
{\left[(45 / 0 /-45 / 90){ }_{n}\right]_{s}} & {[(45 / 0 /-45 / 90) /(45 / 0 /-45 / 90) / \ldots \text { n times }]_{s}}
\end{array}
$$

DESCRIPTION OF INTERLAMINAR STRESS PROBLEMS

The two basic problems studied were the free-edge stress problem (Fig. 1(a)) and the edge delamination problem (Fig. 1(b)). For both cases the laminate is assumed to be long and rectangular. Away from the ends where the loads are applied, the displacements at any $x=$ constant plane are assumed to be given by (refs. 5, 6)

$$
\begin{array}{ll}
u(x, y, z)=\varepsilon_{0} x+v(y, z) \\
v(x, y, z)= & v(y, z) \\
w(x, y, z)= & w(y, z)
\end{array}
$$

The $\varepsilon_{0}$ is the uniform axial strain and $U, v$, and $w$ are functions of $y$ and $z$ only. Equations (1) describe a "quasi-three-dimensional" (Q3D) problem. The modifier "quasi" is used because there are displacements in three directions, but the gradients of $U, v$, and $w$ with respect to the $\mathrm{x}$-coordinate are zero.

For symmetric laminates without delaminations, eqs. (1) rigorously define the displacements. But for unsymmetric laminates or symmetric laminates with delaminations, there is usually a tendency to twist about the $x$ axis. This twist is

$$
\kappa_{x y}=-\frac{\partial^{2} w}{\partial x \partial y}
$$


Since $w$ is not a function of $x$ in eqs. (1), the Q3D formulation imposes the condition $k_{x y}=0$. But in a real laminate, the condition $\kappa_{x y}=0$ cannot be imposed except at the ends of the laminate, where eqs. (1) are not exact. Hence, eqs. (1) make the approximation that $\kappa_{x y}=0$ throughout the laminate.

Equations (1) also impose the condition of zero curvature about the $y$ axis, i.e., $\kappa_{x}=-\frac{\partial^{2} w}{\partial x^{2}}=0$. This condition is closely approximated when a specimen is clamped in a test machine. Hence, imposing $\kappa_{x}=0$ in an analysis is reasonable.

Each ply was idealized as a homogeneous, elastic orthotropic material with the following properties:

$$
\begin{array}{ll}
E_{11}=134 \mathrm{GPa} & \left(19.5 \times 10^{6} \mathrm{psi}\right) \\
E_{22}=E_{33}=10.2 \mathrm{GPa} & \left(1.48 \times 10^{6} \mathrm{psi}\right) \\
G_{12}=G_{13}=G_{23}=5.52 \mathrm{GPa} & \left(0.8 \times 10^{6} \mathrm{psi}\right) \\
\nu_{12}=\nu_{13}=\nu_{23}=0.3 &
\end{array}
$$

These properties are representative of those often assumed for graphite/ epoxy. The subscripts 1, 2, and 3 correspond to the longitudinal, transverse, and thickness directions, respectively, of a zero-degree ply. Also, the uniform axial strain, $\varepsilon_{0^{\prime}}$ was arbitrarily set equal to 0.001 throughout the study.

\section{ANALYSIS}

Two types of analyses were used: Q3D finite element analysis and a laminate theory technique for calculating total strain-energy-release rate, $G_{T}$. The $\mathrm{Q} 3 \mathrm{D}$ analysis was used to obtain free-edge stress distributions and components of the strain-energy-release rates, $G_{I}, G_{I I}$, and $\mathrm{G}_{\text {III }}$ - The laminate theory technique was used because it is inexpensive and yields an interpretation of the effect of laminate thickness on $G_{T}$. 
The theoretical basis of Q3D finite element analysis may be found in reference 6 , so only the application of the Q3D analysis to infinitely thick laminates and the finite element idealization will be discussed.

\section{Infinitely Thick Laminates}

The key aspects of analysis of infinitely thick laminates are: (a) selection of the repeating unit and (b) application of boundary conditions. Consider the infinite laminate $\left[(45 / 0 /-45 / 90)_{s}\right]_{\infty}$ shown schematically in Fig. 2. A representative repeating unit, (45/0/-45/90) $S^{\text {' }}$ is drawn with solid lines. Only a single repeating unit need be analyzed if appropriate boundary conditions can be identified for the upper and lower surfaces of the unit. Note that in the infinite laminate the interface between adjacent units is a plane of symmetry. Consequently, if we impose the condition $\frac{\partial w}{\partial y}=0$ along the upper and lower surfaces of $a$ single repeating unit, that single unit behaves as though it is within an infinitely thick laminate. In the finite element analysis the condition $\frac{\partial w}{\partial y}=0$ along a line is implemented by constraining all nodes along that line to have the same $w$ displacement (but with the net $z$ force $=0$ ). In all cases the repeating unit is a symmetric laminate; hence, in practice only half of the repeating unit was actually modeled if there were no delaminations or the delaminations were symmetrically located about the midplane. Otherwise, the entire repeating unit was analyzed. The same procedure is used whether or not the laminate has a delamination. However, note that placing a delamination in the repeating unit causes every similar interface in the infinite laminate to have the same delamination. 
Finite Element Idealizations

Because of symmetries in the problems shown in Figure 1, only onequarter of a representative $\mathrm{x}=$ constant plane was modeled. Figure $3(\mathrm{a})$ shows a typical model for the edge stress analysis of a symmetric 8-ply laminate. The model has 792 nodes and 736 four-node isoparametric quadrilateral elements. Models for other laminate thicknesses had the same degree of mesh refinement. All the models had a laminate width to thickness ratio, $2 b / t$, of at least 15 .

For both finite and infinitely thick laminates the displacement functions $U$ and $V$ were prescribed to be zero along the line $y=0$ and W was prescribed to be zero along the line $z=0$. For the infinitely thick laminates all nodes lying on the line $z=4 h$ were constrained to have the same displacement $w$, with the net force in the $z$-direction on these nodes set equal to zero.

Figure 3(b) shows a typical model for a 16-ply laminate with a delamination. The laminate width to thickness ratio, $2 b / t$, was at least 5 for all models. The delamination length to ply thickness ratio, a/h, was at least 20. Around the delamination tip, square elements with sides of length $\mathrm{h} / 4$ were used. Strain-energy-release rates $G_{I}, G_{I I}$, and $G_{I I I}$ were calculated using the virtual crack closure method (ref. 7).

Classical Laminate Theory Analysis

The laminate theory technique for calculating total strain-energyrelease rate, $G_{T}$, is based on dividing a laminate into two types of regions: in one type the strain energy varies linearly with delamination length, and in the other type the strain energy is independent of delamination length (ref. 8). A long delamination is assumed (i.e., a delamination length of more than twice the laminate thickness). 
Consider the laminate in Fig. 4, which is divided into four regions. Regions I and III are away from geometric discontinuities, i.e., either the crack tip or the free edge. Hence, the stress distributions in these regions are defined by laminate theory and are independent of delamination length. The strain energy in regions I and III vary linearly with delamination length (since the volume in each region changes linearly). Regions II and IV have complex stress distributions because of the crack tip and free edge, respectively. But the stress distributions are independent of delamination length. Also the volume in each region stays constant. Hence, the strain energy in regions II and IV is independent of delamination length.

In this study $\varepsilon_{\mathrm{X}}$ was held constant. Hence, $G_{T}$ is given by the change in strain energy in regions I-IV. But as previously discussed, only the strain energy in regions I and III vary with delamination length. Reference 2 showed that this change in strain energy could be expressed as

$$
G_{T}=\frac{\varepsilon_{x}{ }^{2} t}{2 n}\left(E_{I}-E_{I I I}\right)
$$

where $E_{I}$ and $E_{I I I}$ are the axial Young's moduli of regions $I$ and III respectively and $\mathrm{n}$ is the number of delaminations.

In reference 2 the axial Young's moduli are calculated using CLT implicitly assuming $\mathrm{N}_{\mathrm{y}}=\mathrm{N}_{\mathrm{xy}}=\mathrm{k}_{\mathrm{x}}=\mathrm{k}_{\mathrm{y}}=\mathrm{k}_{\mathrm{xy}}=0$. For example the axial modulus $\mathrm{E}_{\mathrm{I}}$ would be

$$
E_{I}=\frac{1}{x_{11} t}
$$

where $x_{1}$ is the $(1,1)$ element of the inverse extensional stiffness matrix for region $I, A_{i j}^{-1}$, and $t$ is the thickness of the laminate. 
For some laminates equation (6) is sufficiently accurate, as demonstrated in reference 2. However, if the laminate or sublaminate exhibits strong extension-bending coupling, the above technique requires modification. This modified technique still uses CLT to calculate the axial modulus, but the calculation is performed assuming $\mathrm{N}_{\mathrm{y}}=\mathrm{N}_{\mathrm{xy}}=\mathrm{k}_{\mathrm{x}}=\mathrm{M}_{\mathrm{y}}=\mathrm{k}_{\mathrm{xy}}=0$ and $\varepsilon_{\mathrm{X}}=\varepsilon_{0}$. These assumptions are consistent with those made in the Q3D finite element analysis. The effective axial modulus $\hat{E}$ is then

$$
\hat{E}=\frac{N_{x}}{t \varepsilon_{0}}
$$

The laminate theory analysis was also used to analyze infinitely thick laminates synthesized by stacking "repeating units." The procedure is conceptually the same as used in the $Q 3 \mathrm{D}$ analysis; the difference is in the implementation. In the laminate theory analysis, lines of symmetry between repeating units are accounted for by imposing zero curvatures $\kappa_{x^{\prime}} k_{y^{\prime}}$ and $\kappa_{x y}$. For infinitely thick laminates, the thickness $t$ is that for the repeating unit.

\section{RESULTS AND DISCUSSIONS}

First, the interlaminar stresses near the free edge of undelaminated laminates will be discussed. Presumably delamination initiation is governed by these stresses. The magnitudes of these stresses near the free edge are well known to depend on the finite element mesh refinement. In fact, the stresses are singular (mathematically) at the intersections of the free edge and the ply interfaces. But the finite values calculated by the finite element analysis do estimate the intensity of the stress field. Hence, the calculated stresses do qualitatively show the effect of laminate thickness on interlaminar stresses. Secondly, laminates with 
delaminations are considered. Strain-energy-release rates will be used to characterize the effect of laminate thickness on interlaminar stresses near the tip of a delamination. Finally, a few experimental results from the literature will be interpreted based on the analytical study.

Free-Edge Interlaminar Stresses

Free-edge interlaminar stresses depend on differences in the mechanical properties of the various plies in a laminate and the stacking sequence. For thin laminates simple equilibrium arguments can be used to show the effect of stacking sequence on $\sigma_{z}$. For example, using equilibrium arguments the midplane $\sigma_{z}$ for a $(45 / 0 /-45 / 90)_{s}$ laminate is predicted to have a large tensile value for tensile applied load. Similar arguments predict a large compressive $\sigma_{z}$ at the midplane for the reversed stacking sequence, $(90 /-45 / 0 / 45)_{S}$. But the infinitely thick counterparts for both of these laminates is $\left[(45 / 0 /-45 / 90)_{S}\right]_{\infty}$ i that is, $\left[(45 / 0 /-45 / 90)_{s}\right]_{\infty}$ is the same as $\left[(90 /-45 / 0 / 45){ }_{s}\right]_{\infty}$. Obvious $l y$, the effect of "stacking sequence" becomes clouded for thick laminates.

To investigate the effect of laminate thickness on free-edge interlaminar stresses, several laminates synthesized by stacking ply groups of $(45 / 0 /-45 / 90)$ were analyzed. The laminates considered were: $(45 / 0 /-45 / 90)_{s},(90 /-45 / 0 / 45)_{s^{\prime}}\left[(45 / 0 /-45 / 90)_{s}\right]_{\infty},(45 / 0 /-45 / 90 / 90 /-45 / 0 / 45)_{s^{\prime}}$ $(45 / 0 /-45 / 90 / 45 / 0 /-45 / 90)_{s}{ }^{\prime}$ and $\left[(45 / 0 /-45 / 90 / 45 / 0 /-45 / 90)_{s}\right]_{\infty}$. First, the effect of laminate thickness on free-edge stresses for interior ply groups was examined. Eight-ply and infinitely thick laminates were used in this first phase. Next, two 16-ply laminates were examined to determine how laminate thickness affects the response of exterior ply groups and whether the interior ply groups of a 16-ply laminate behave as though they were 
inside an infinitely thick laminate. Finally the effect of laminate thickness on free-edge boundary layer width was examined.

The effect of laminate thickness on the free-edge stresses for interior ply groups was determined by analyzing three related laminates: $(45 / 0 /-45 / 90)_{s},(90 /-45 / 0 / 45)_{s}$, and $\left[(45 / 0 /-45 / 90)_{s}\right]_{\infty}$. Note that because of symmetries, $\left[(45 / 0 /-45 / 90)_{s}\right]_{\infty}$ is identical to $\left[(90 /-45 / 0 / 45)_{s}\right]_{\infty}$. Hence, the infinitely thick laminate is related to both 8-ply laminates. Figure 5 shows the distribution of $\sigma_{z}$ and $\sigma_{x z}$ through the thickness of the specimen at the free edge. These stresses reach their maximum calculated values at different interfaces: $\sigma_{z}$ is large at $z=0$ and $h$ and $\sigma_{x z}$ is large at $z=2 h$ and $3 h$. The infinitely thick counterpart, $\left[(45 / 0 /-45 / 90)_{S}\right]_{\infty}$ has very similar stress distributions (see Fig. 6). The $\sigma_{z}$ distribution for the infinite laminate is shifted in the compression direction, but the shape of the curve is similar, except in the 45 degree ply where the infinite laminate has significant compressive $\sigma_{z}$. In contrast, the $\sigma_{x z}$ distributions for the two laminates are nearly identical. Figure 7 shows the $\sigma_{z}$ distributions from Figures 5 and 6 along with the $\sigma_{z}$ distribution for the $(90 /-45 / 0 / 45)_{s}$ laminate. Note that the $\sigma_{z}$ distribution for the infinitely thick laminate is approximately an average of the $\sigma_{z}$ distributions for the two related 8-ply laminates. The infinitely thick laminate has the detrimental characteristics of both thin laminates - it has both large tension and compression $\sigma_{z^{*}}$ But the maximum tensile and compressive values are less than those in the two 8-ply laminates. The response of interior and exterior ply groups was studied using two 16-ply laminates: $(45 / 0 /-45 / 90 / 90 /-45 / 0 / 45)_{S}$ and $(45 / 0 /-45 / 90 / 45 / 0 /-45 / 90)_{s}$. Figure 8 shows the through-thickness $\sigma_{z}$ and $\sigma_{x z}$ distributions for the 
$(45 / 0 /-45 / 90 / 90 /-45 / 0 / 45)_{s}$ laminate. Stress distributions for $(45 / 0 /-45 / 90)_{s}$ and $\left[(45 / 0 /-45 / 90)_{s}\right]_{\infty}$ are superimposed on the $16-p l y$ results. The $\sigma_{z}$ and $\sigma_{x z}$ distributions for the interior plies, i.e., $z=0$ to $4 \mathrm{~h}$, are very similar to that for $\left[(45 / 0 /-45 / 90)_{s}\right]_{\infty}$ in which all the plies are interior plies. But from $z=4 \mathrm{~h}$ to $8 \mathrm{~h}$ the $\sigma_{z}$ and $\sigma_{x z}$ distributions are very similar to that for $(45 / 0 /-45 / 90)_{s}$, in which there is no interior group of $(45 / 0 /-45 / 90)$ plies. Apparently $\sigma_{z}$ and $\sigma_{x z}$ are governed by the neighboring plies. Furthermore, the effect of the top surface (i.e., $z=8 \mathrm{~h}$ ) does not propagate far into the laminate. This interpretation was verified by examining another $16-\mathrm{ply}$ laminate, $(45 / 0 /-45 / 90 / 45 / 0 /-45 / 90)_{s}{ }^{\circ}$ In the region $4 \mathrm{~h}<\mathrm{z}<8 \mathrm{~h}$, the $\sigma_{z}$ and $\sigma_{x z}$ distributions are nearly the same as that for a $(45 / 0 /-45 / 90)$ s laminate (see Fig. 9). Hence, $(45 / 0 /-45 / 90)_{s^{\prime}}(45 / 0 /-45 / 90 / 90 /-45 / 0 / 45)_{s^{\prime}}$ and $(45 / 0 /-45 / 90 / 45 / 0 /-45 / 90)_{s}$ laminates all have approximately the same $\sigma_{z}$ and $\sigma_{x z}$ distributions in the outer four plies, even though the remaining plies are much different for each laminate. Near $z=4 \mathrm{~h}$ in the $(45 / 0 /-45 / 90 / 45 / 0 /-45 / 90)_{\mathrm{s}}$ laminate (Fig. 9), the stress distributions are not matched by those for $\left[(45 / 0 /-45 / 90)_{s}\right]_{\infty}$. This is because the stacking sequence near $z=4 \mathrm{~h}$ in the 16-ply laminate is different from that found anywhere in the infinite laminate. But near $z=0$, the stacking sequence is the same as that in the infinite laminate; concomitantly, the $\sigma_{z}$ distributions agree very well.

The effect of laminate thickness on the free-edge boundary layer width was also examined. This effect was qualitatively assessed by comparing the variation of $\sigma_{z}$ in the width direction near the free edge. Figure 10 shows the through-width $\sigma_{z}$ distributions for several laminates along 90-90 interfaces. 
The boundary layer width is less for an infinitely thick laminate than for the corresponding finite thickness laminate. That is, the width is less for $\left[(45 / 0 /-45 / 90)_{s}\right]_{\infty}$ than for $(45 / 0 /-45 / 90)_{s}$ (Fig. $\left.10(a)\right)$. Hence, the boundary layer width does not necessarily increase with laminate thickness. Increasing the number of plies in the repeating unit can increase the boundary layer width, as evidenced by the results for $\left[(45 / 0 /-45 / 90)_{s}\right]_{s}$, which has 8 plies in the repeating unit, and $(45 / 0 /-45 / 90 / 45 / 0 /-45 / 90)_{s}$, which has 16 plies in the repeating unit (Fig. 10(b)). (Of course, for this 16-ply laminate there is only a single "repeating" unit.) By increasing the number of plies in the repeating unit, a laminate becomes less homogeneous, which causes a larger boundary layer width.

Strain Energy Release Rates:

As stated earlier two types of analyses were used to calculate strain energy release rates: a laminate theory analysis and a Q3D finite element analysis. First the laminate theory analysis will be used to show the effect of laminate thickness on total strain energy release rates. Then the Q3D analysis will be used to show the effect of laminate thickness on the relative magnitudes of $G_{I}, G_{I I}$, and $G_{I I I}$. The strain-energy release rates are divided by $h$ in the figures, since the strain-energy release rates vary linearly with $\mathrm{h}$.

\section{Classical Laminate Theory Results}

Delamination can occur at a, single interface or at several interfaces. The possible combinations of delaminations are too numerous to examine them all individually. Instead two patterns of delaminations were considered: a single delamination at $z=n h$ and delaminations at $z= \pm n h$. The two 
delaminations at $z= \pm n h$ were assumed to extend simultaneously. Recall that for infinitely thick laminates, all repeating units have delaminations at similar interfaces.

Delaminations at $z=n h$ and $z= \pm n h$ in $(45 / 0 /-45 / 90)_{s}$ and $\left[(45 / 0 /-45 / 90){ }_{S}\right]_{\infty}$ were studied first. For the infinitely thick laminate, each repeating unit (which consists of 8 plies) has the delaminations indicated. Figure 11 shows the results for these laminates. Specimen thickness has virtually no effect on the total strainenergy-release rate, $G_{T^{\prime}}$ when the delaminations are at $z= \pm h, \pm 2 h$, or $\pm 3 h$. But for single delaminations at $z=0, h, 2 h$, or $3 h$, there are large differences; $G_{T}$ for the infinitely thick laminate is always much smaller than for the 8-ply laminate. The most striking case is at $z=0$ where $G_{T}$ is identically zero for the infinite laminate, but is very large for the 8-ply case.

These trends can be easily explained by examining the basis of the CLT analysis. Changes in axial modulus are what contribute to $G_{T}$. $A$ delamination at $z=0$ in the infinitely thick laminate simply divides the original quasi-isotropic laminate into many individual quasi-isotropic laminates. But the axial modulus of a quasi-isotropic laminate is independent of thickness or stacking sequence. Hence, $G_{T}$ is zero. For $z=h, 2 h$, and $3 h$ the differences are not as dramatic, but still a delamination in each repeating group does not affect the axial modulus of a thick laminate nearly as much as it does for a thin laminate. Hence, $G_{T}$ is smaller for the thick laminate. .

Recall that Figures 5 and 6 showed that for an undelaminated specimen, $\sigma_{z}$ and $\sigma_{x z}$ distributions along the free edge were nearly the same for the 8-ply and the infinite-ply laminates. But Figure 11 shows that 
$G_{T}$ is identically zero for a delamination at $z=0$ in an infinitely thick laminate, and $G_{T}$ is large for a delamination at $z=0$ in an 8-ply laminate. Since $G_{T}$ is a measure of the intensity of the stress field around a delamination tip, there appears at first to be a contradiction. This apparent contradiction is a result of the way $G_{T}$ varies with delamination length, $a$, at the midplane as shown in Figure 12. (These results were obtained with the Q3D finite element analysis.) Note that $\mathrm{G}_{\mathrm{T}}$ increases with "a" initially, as would be expected for a delamination initiating in a stressed material. But with further increase in delamination length, $G_{T}$ decreases to zero and remains zero for further growth. The laminate theory technique always calculates the "steady-state" value, which in this case is zero.

These observations indicate that there may be a correlation between free-edge interlaminar stresses before delamination initiation and strainenergy-release rate right after delamination initiation. But after the delamination grows away from the free edge, there is not necessarily any correlation between the original free-edge stresses and the strain-energyrelease rate.

Next, $(45 / 0 /-45 / 90 / 45 / 0 /-45 / 90)_{s}$ and $\left[(45 / 0 /-45 / 90 / 45 / 0 /-45 / 90)_{s}\right]_{\infty}$ laminates were examined. The repeating group in these laminates consists of 16 plies. As in the cases studied earlier, $G_{T}$ for the infinite laminate is less than or equal to $G_{T}$ for the thinner laminate (see Fig. 13). The last phenomenon studied using the laminate theory analysis was the effect of delamination location on $G_{T}$. Only a single delamination is assumed to exist. The laminates examined were $\left[(45 / 0 /-45 / 90)_{s}\right]_{n}, n=2$, 4, 8. Figure 14 shows the results for these 16-, 32-, and 64-ply laminates. A delamination far from the top surface of the laminate affects the axial 
stiffness very little. Hence, the corresponding $G_{T}$ is small. For thin laminates, e.g., the 16-ply laminate, all of the plies can be considered to be near the top surface. Concomitantly, for the 16-ply laminate there is no distinct "interior region" in which $G_{T}$ is small. But for the 32and 64-ply laminates there is a distinct region in which $G_{T}$ is small. Note that for these three laminates, the interface which corresponds to maximum $G_{T}$ is the fifth interface from the top surface (i.e., at $z=(4 n-5) h)$. Furthermore, the maximum value appears to be asymptotically decreasing to a constant value as the laminate thickness increases. Apparently the behavior (in terms of $G_{T}$ ) of the plies near the surface is nearly independent of the laminate thickness. Recall that the free-edge stresses for the plies near the surface discussed earlier were also nearly independent of the laminate thickness.

These results predict that, based on total-strain-energy-release rates, delaminations would be expected to grow most easily near the top surface rather than the interior of a thick laminate. Also, outer plies of a thick laminate should be less prone to delaminate than the outer plies of a thin laminate. Furthermore, since the thick laminate has a smaller percentage of outer plies than a thin laminate, the percentage of delaminated interfaces should also decrease as the laminate thickness increases.

Finite Element Results

The CLT analysis calculates only the total strain-energy-release rates. To determine the relative magnitudes of $G_{I}, G_{I I}$ and $G_{I I I}$, Q3D finite element analysis was used.

Eight-, 16-, and 32-ply laminates and infinitely thick laminates with 8-, 16-, and 32-ply repeating groups were analyzed. The finite thickness 
laminates were analyzed for the cases of a single delamination and two delaminations located symmetrically about the midplane. In all cases the delaminations were assumed to be at $-45 / 90$ interfaces. Tables $1-3$ present the total strain-energy-release rates, $G_{T^{\prime}}$ and the $G_{I} / G_{T}$ ratio for the various cases. In all cases studied the mode III component was negligible.

For single delaminations in a finite thickness laminate (Table 1), the $G_{I} / G_{T}$ ratio is largest at the first $-45 / 90$ interface from the top surface. As the laminate thickness is increased, the $G_{I} / G_{T}$ ratio at this interface decreases slightly. The mode I percentage decreases as the distance from the top surface increases until the midplane is approached (see results for $32-\mathrm{ply}$ laminates). The increase in $\mathrm{G}_{\mathrm{I}} / \mathrm{G}_{\mathrm{T}}$ near the midplane is probably due to the symmetry of the laminate about the midplane. This symmetry creates a pure mode I situation for a delamination at the midplane. The maximum value of $G_{T}$ occurs when a delamination is at the fifth interface from the top surface. (Note that for an 8-ply laminate, this interface could be considered either the third or fifth interface from the top surface.) This result is consistent with the CLT results in Figure 11.

Table 2 shows the results for finite thickness laminates with two symmetrically located delaminations. The effects of delamination location through the thickness and laminate thickness on $G_{I} / G_{T}$ are the same as observed for single delaminations (Table 1). Comparison of Tables 1 and 2 show that $G_{T}$ values are different for single and double delaminations, but the $G_{I} / G_{T}$ ratios are about the same for the same laminate with similarly located delaminations. However, as the laminate thickness increases, the differences between the $G_{T}$ for single and double delaminations decrease, except when the delaminations are near the midplane. 
In contrast to the results above, the infinitely thick laminates (Table 3) have essentially no mode I component. As mentioned earlier, GII was negligible. Hence, the strain-energy-release rate is essentially all mode II.

Comparison of Analysis and Experiments

The analyses presented earlier were used to discuss a few relevant experimental results in the literature.

The static unnotched failure strains of $[45 / 0 /-45 / 90]_{\mathbf{s}}$ and $[45 / 0 /-45 / 90]_{2 s}$ graphite/epoxy laminates (T300/5208) have been measured as $0.854 \%$ (ref. 3) and $1.03 \%$ (ref. 4), respectively. The specimens tested in reference 3 and 4 were manufactured about the same time by the same vendor. The [45/0/-45/90 $]_{\mathrm{s}}$ laminate showed extensive delamination growth before final failure. In contrast, the $[45 / 0 /-45 / 90] 2$ s laminate did not show any delaminations prior to final failure, even though the final failure strain was much larger. Free-edge stresses and strain-energyrelease rates were examined to determine whether one would expect the $[45 / 0 /-45 / 90]_{s}$ laminate to delaminate and the $[45 / 0 /-45 / 90]_{2 s}$ laminate not to delaminate. Figures 5 and 9 show both laminates have large interlaminar normal and shear stresses at the free edge. In fact, the peak values of these stresses are nearly the same for the two laminates. Hence, the free-edge stress distributions do not explain why the 8-ply laminate is more prone to delaminate than the 16-ply laminate. Strain-energy-release rates are not strictly applicable to delamination initiation, since the G's are zero for zero delamination length. But the G's increase quickly to constant values as a delamination grows (ref. 2). Hence, if small initial flaws are assumed to exist, the G's calculated herein are appropriate for predicting delamination growth. 
The strain-energy-release rates for the two laminates are quite different. Figures 11 and 13 show that for the same strain level, $G_{T}$ is much larger for a delamination in a $[45 / 0 /-45 / 90]_{s}$ laminate than for a $[45 / 0 /-45 / 90]_{2 s}$ laminate, for both single and two symmetric delaminations. Based on $G_{T^{\prime}}$ one would predict a single delamination to grow in the 8-ply laminate along $\mathrm{z}=\mathrm{h}$.

In the tests (ref. 3) a single delamination did form in the 8-ply laminate, but it wandered back and forth from one $-45 / 90$ (i.e. $z=h$ ) interface across the $90 \mathrm{deg}$ plies to the other $-45 / 90$ interface (see Fig. 15). This pattern of growth cannot be rigorously analyzed using either the Q3D or the laminate theory analysis, since the problem is fully three-dimensional. The actual $G_{T}$ was assumed to fall between $G_{T}$ calculated for a delamination at $z=0$ and $G_{T}$ for a delamination at $z=h$, since the actual delamination path is bounded by $z= \pm$. Since $G_{T}$ for a delamination at $z=0$ is larger than the maximum $G_{T}$ for the 16-ply laminate, one would still predict the 8-ply laminate to delaminate at a lower strain than the 16-ply laminate.

The possibility that delamination growth is governed by the magnitude of the mode $I$ component $G_{I}$ was also considered. Except for midplane delamination, for which $G_{I}=G_{T^{\prime}}$ the $Q 3 D$ analysis is required to determine the mode I component. Q3D analysis was performed for delaminations at $z=h$ and $z= \pm 2 h$ for both laminates. The 16-ply 'laminate was also analyzed for a delamination at $z=5 \mathrm{~h}$. These interfaces were chosen because $G_{T}$ was large at these interfaces. Table 4 shows the results. Based on $G_{I}$ one would predict the 8-ply laminate to delaminate at a lower strain level than the 16-ply laminate. The delamination in the 8-ply laminate should grow along the midplane $(i \cdot e \cdot z=0)$. For a 
delamination in the 8-ply laminate along $z=h$ (where $G_{T}$ is largest), $G_{I}$ is still much larger than that for any of the 16-ply cases. Assuming the actual $G_{I}$ is bounded by the results for delaminations at $z=0$ and $z=h$, one would predict (correctly) that the 8-ply laminate should delaminate at a lower strain level than the 16-ply laminate.

The critical value of $G_{I}$ for delamination growth $\left(G_{I C}\right)$ in $T 300 / 5208$ is approximately $100 \mathrm{~J} / \mathrm{m}^{2}$ (ref. 9). Assuming that delamination growth occurs when $G_{I C}$ is reached, the previous analytical results can be used to predict when delamination should occur for each laminate.

For the 8-ply laminate the average value of $G_{I}$ for delaminations at $z=0$ and $z=h$ was used (i.e. $G_{I} / h$ for $\varepsilon_{0}=0.001$ is $\left.(20.62+13.48) / 2=17.05 \mathrm{~J} / \mathrm{m}^{3}\right)$. The ply thickness $\mathrm{h}$ was assumed to be $1.397 \times 10^{-4} \mathrm{~m}$. The strain-energy-release rate varies as $\varepsilon_{0}^{2}$. Hence,

$$
\left(\frac{\varepsilon_{0}^{C R}}{.001}\right)^{2} 17.05 \mathrm{~kJ} / \mathrm{m}^{3}=\frac{G_{I C}}{h}=\frac{100 \mathrm{~J} / \mathrm{m}^{2}}{1.397 \times 10^{-4} \mathrm{~m}}
$$

where $\varepsilon_{0}^{C R}$ is the strain at which delamination should occur. Solving equation (8), one obtains $\varepsilon_{0}^{C R}=0.658$. In reference $3 \varepsilon_{0}^{C R}$ is not reported. But the stress-strain curve is reported and becomes nonlinear (probably due to delamination) between 0.68 to 0.78 strain. Hence, the agreement between analysis and experiments is excellent.

For the 16-ply laminate the largest $G_{I}$ occurs for delamination at $z=0$ (see Table 4). The magnitude of $G_{I} / h$ for $\varepsilon_{0}=0.001$ is $9.79 \mathrm{~kJ} / \mathrm{m}^{3}$. proceeding as for the $8-\mathrm{ply}$ laminate, $\varepsilon_{0}^{\mathrm{CR}}$ is predicted to be $0.86 \%$. In the actual test the specimen failed at a strain of 18 without delaminating. of course, whether delamination growth was imminent when failure occurred is not known. 
Compression-compression fatigue test results for $[90 / 45 / 0 /-45]_{\mathrm{ns}} \mathrm{G} / \mathrm{E}$ laminates have been reported in reference 10 . In these tests the first delamination was observed to initiate near an outside ply. Subsequent delaminations formed farther in the interior of the laminate (i.e., closer to the midplane). This behavior is consistent with the analytical results discussed earlier; i.e., the total strain-energy-release rate and the percentage of $G_{I}$ tend to be larger for delamination growth near the outside plies.

\section{CONCLUSIONS}

Analyses were conducted to determine the effect of laminate thickness on the interlaminar stresses in rectangular laminates under uniform axialstrain. Laminate thicknesses ranged from 8-ply to infinitely thick. All the laminates were quasi-isotropic. They were synthesized from $(45 / 0 /-45 / 90)$ ply groups. For laminates without delamination, free-edge stresses were examined; for laminates with delamination, strain-energyrelease rates were used to characterize the interlaminar stresses at the delamination tip. Quasi-three-dimensional finite element analysis and classical laminate theory analysis were used in the study. Based on the results from these analyzes, the following conclusions were made: 1. If thick laminates are synthesized by stacking repeating units, then

(a) the interlaminar normal stress distribution in the outer group of plies is insensitive to the total laminate thickness,

(b) the interlaminar normal stress distribution for the interior group of plies is nearly the same as that for an infinitely thick laminate.

(c) The interlaminar shear stress distribution is very insensitive to the total laminate thickness. 
2. The free-edge boundary layer width is related to the thickness of the repeating unit, not the total laminate thickness.

3. Free-edge interlaminar stresses can be used only for locating delamination initiation. After a delamination grows away from the free edge, the original free-edge stresses provide no information on the intensity of the stress field at the delamination tip.

4. Delaminations near the top and bottom surfaces of a thick laminate have larger total strain-energy-release rates, $G_{T^{\prime}}$ and mode I-tototal $\left(G_{I} / G_{T}\right)$ ratios than delaminations deep in the interior of the laminate. Therefore, delaminations can be expected to grow most easily near the surface of a laminate. This expectation is consistent with experimental results in the literature. Also, near surface delaminations in thin laminates tend to have larger strain-energy release rates than corresponding near surface delaminations in thick laminates. Therefore, near surface delaminations can be expected to grow more easily in a thin laminate than in a thick laminate. 


\section{REFERENCES}

1. Rodini, B. T., Jr.; and Eisenmann, J. R., in Fibrous composites in Structural Design, Plenum, New York, 1980, pp. 441-457.

2. O'Brien, T. K.: Characterization of Delamination Onset and Growth in a Composite Laminate. Damage in Composite Materials, ASTM STP 775, 1982, pp. 140-167.

3. Garber, D. P.: Tensile Stress-Strain Behavior of Graphite/Epoxy Laminates. NASA CR 3592, Aug. 1982.

4. Kennedy, J. M.: Tensile Stress-Strain Behavior of Hybrid Composite Laminates. Proceedings of the Society for Experimental stress Analysis 1983 Spring Conference, Brookfield, CT, May 1983, pp. 272-279.

5. Pipes, R. B.; and Pagano, N. J.: Interlaminar Stresses in Composite Laminates Under Uniform Axial Extension. J. Composite Materials, vol. 4, pp. 538-548, 1970 .

6. Wang, A. S. D.; and Crossman, F. W.: Some New Results on Edge Effect in Symmetric Composite Laminates. J. Composite Materials, vol. 11, Jan. 1977, pp. 92-106.

7. Rybicki, E. F.; and Kanninen, M. F.: A Finite Element Calculation of Stress Intensity Factors by a Modified Crack Closure Integral. Engineering Fracture Mechanics, vol. 9, 1977, pp. 931-938.

8. Roderick, G. L.; Everett, R. A., Jr.; and Crews, J. H., Jr.: Cyclic Debonding of Unidirectional Composite Bonded to Aluminum Sheet for Constant Amplitude Loading. NASA TN D-8126, 1976.

9. Ramkumar, R. L.: Performance of a Quantitative Study of InstabilityRelated Delamination Growth. NASA CR-166046, March 1983.

10. Harris, C. E.; and Morris, D. H.: An Evaluation of the Effects of Stacking Sequence and Thickness on the Fatigue Life of QuasiIsotropic Graphite/Epoxy Laminates. Technical Report VPI-E-83-16, virginia Polytechnic Institute and State University, Blacksburg, VA, April 1983. 


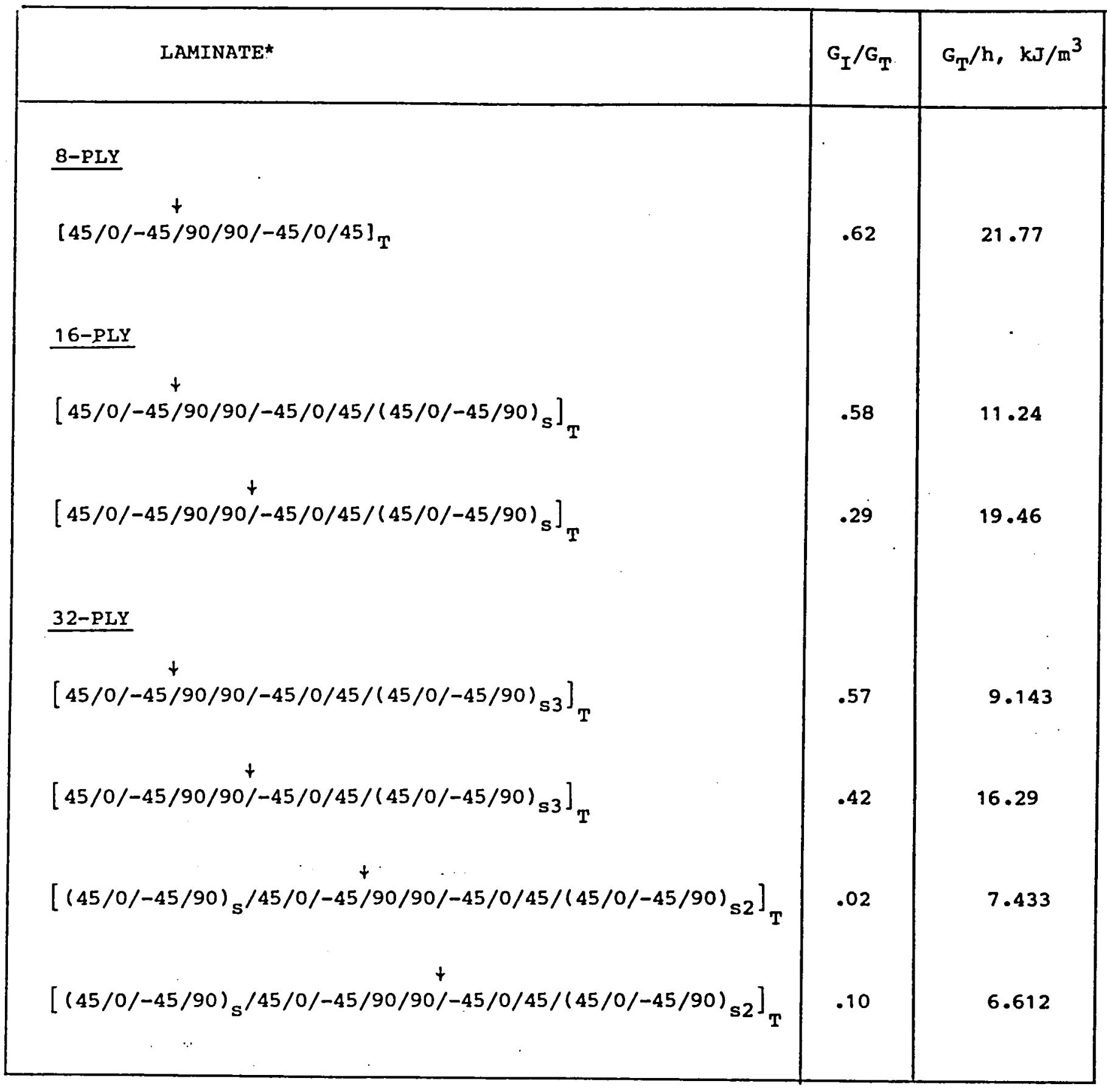

* " $\downarrow "$ INDICATES DELAMINATION LOCATION

TABLE 1.- Strain-energy release rates for various laminates with a single delamination. 


\begin{tabular}{|c|c|c|}
\hline LAMINATE ${ }^{\star}$ & $\mathrm{G}_{\mathrm{I}} / \mathrm{G}_{\mathrm{T}}$ & $\mathrm{G}_{\mathrm{T}} / \mathrm{h}, \mathrm{kJ} / \mathrm{m}^{3}$ \\
\hline 8-PLY & & \\
\hline$[45 / 0 /-45 / 90]_{s}$ & .62 & 12.82 \\
\hline 16-PLY & & . \\
\hline$\underset{[45 / 0 /-45 / 90 / 90 /-45 / 0 / 45]_{s}}{t}$ & .55 & 9.474 \\
\hline$\stackrel{+}{+} \underset{[45 / 0 /-45 / 90 / 90 /-45 / 0 / 45]_{\mathrm{s}}}{ }$ & .22 & 21.93 \\
\hline 32-PLY & & \\
\hline$\left[45 / 0 /-45 / 90 / 90 /-45 / 0 / 45 /(45 / 0 /-45 / 90)_{s}\right]_{s}$ & .57 & 8.488 \\
\hline$\left[45 / 0 /-45 / 90 / 90 /-45 / 0 / 45 /(45 / 0 /-45 / 90)_{s}\right]_{s}$ & .452 & 15.71 \\
\hline$\left[(45 / 0 /-45 / 90)_{s} / 45 / 0 /-45 / 90 / 90 /-45 / 0 / 45\right]_{s}$ & .01 & 7.081 \\
\hline$\left[\begin{array}{c}+ \\
{\left[(45 / 0 /-45 / 90)_{\mathrm{s}} / 45 / 0 /-45 / 90 / 90 /-45 / 0 / 45\right.}\end{array}\right]_{\mathrm{s}}$ & .03 & 11.34 \\
\hline
\end{tabular}

* $"$ " INDICATES DELAMINATION LOCATION

TABLE 2.- Strain-energy release rates for various laminates with two symmetrically located delaminations. 


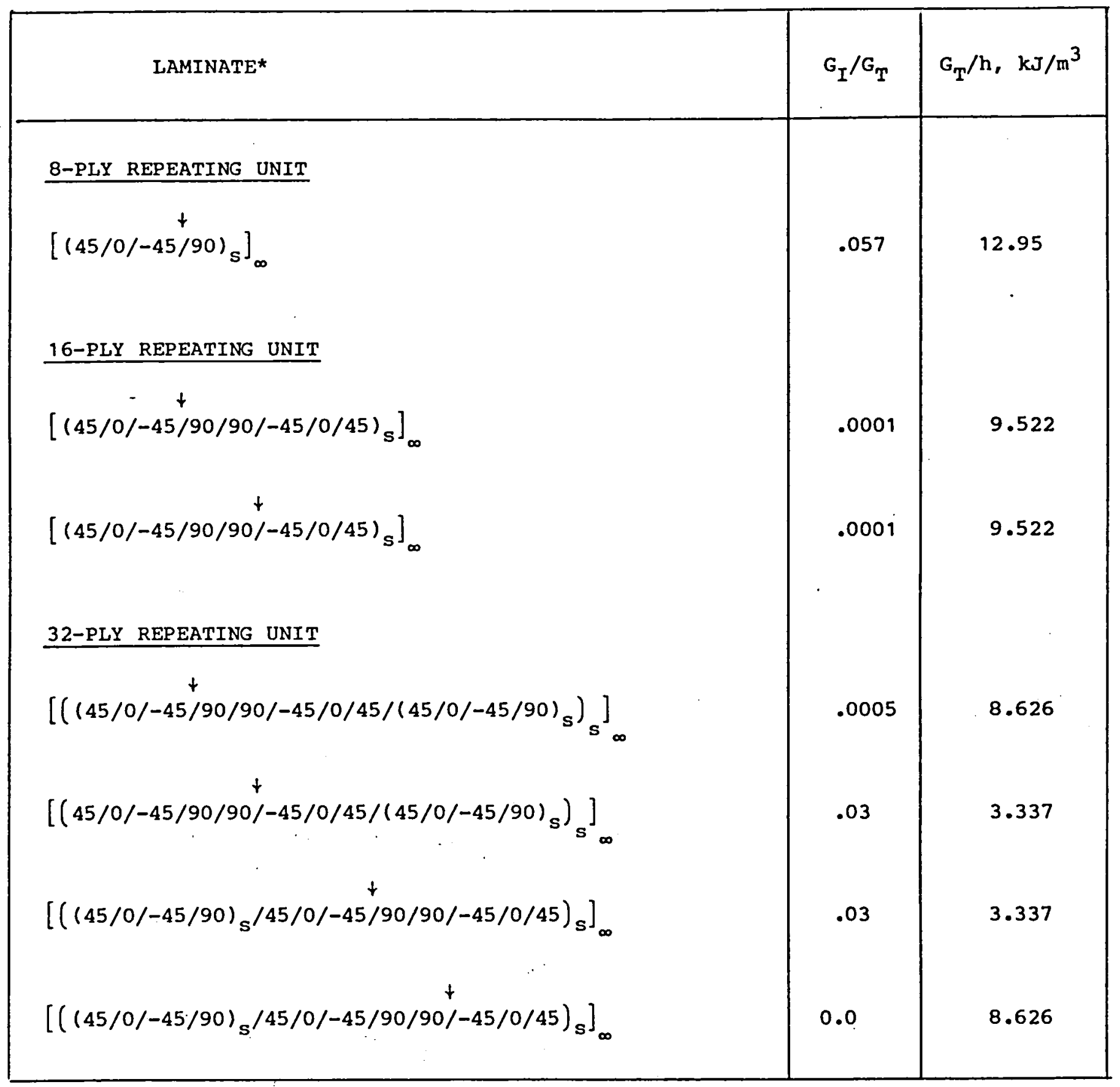

* $" \downarrow$ " Indicates Delamination location

TABLE 3.- Strain-energy release rates for various infinitely thick laminates. 


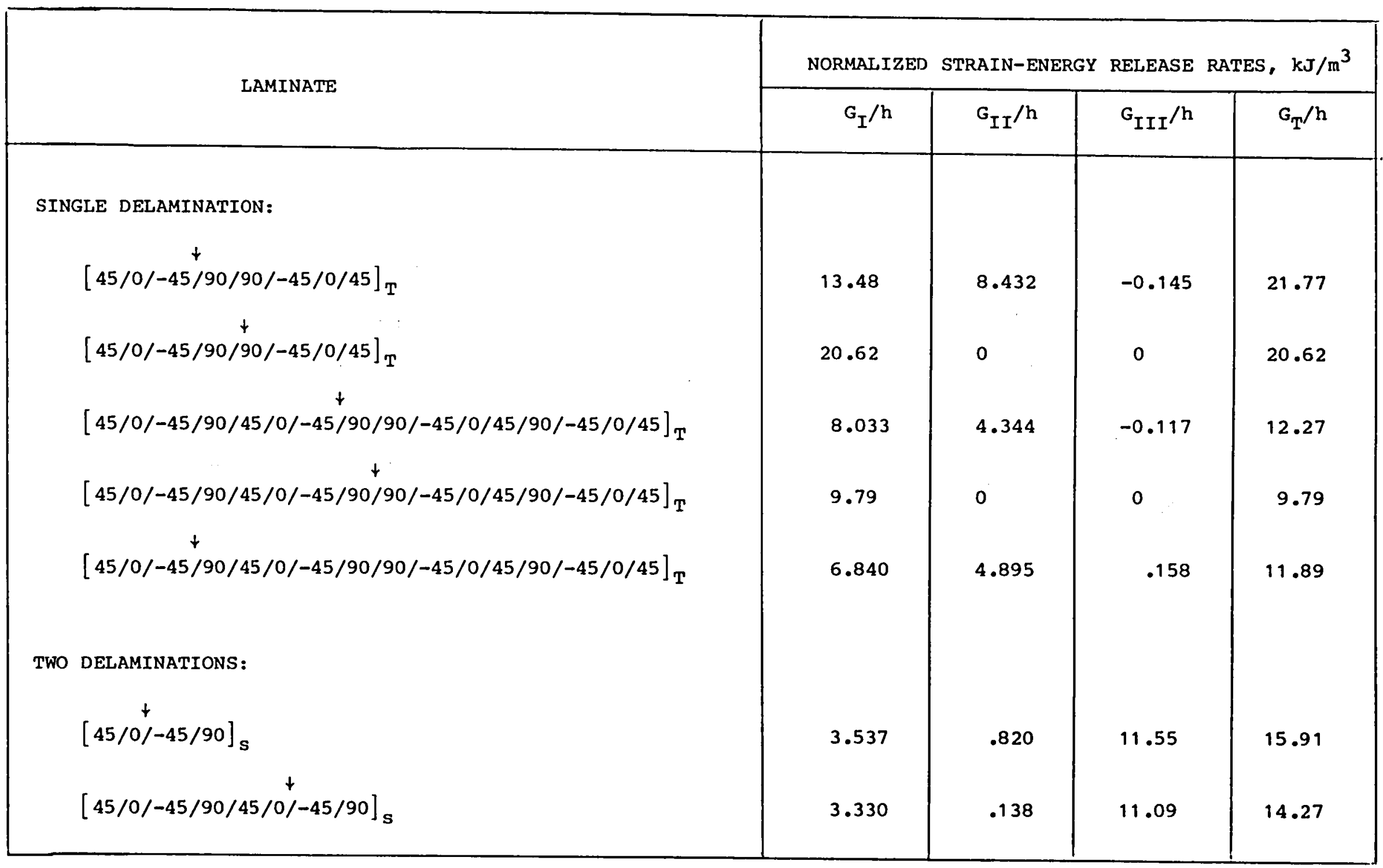

TABLE 4.- Strain-energy release for laminates tested in references 1 and 2 . 

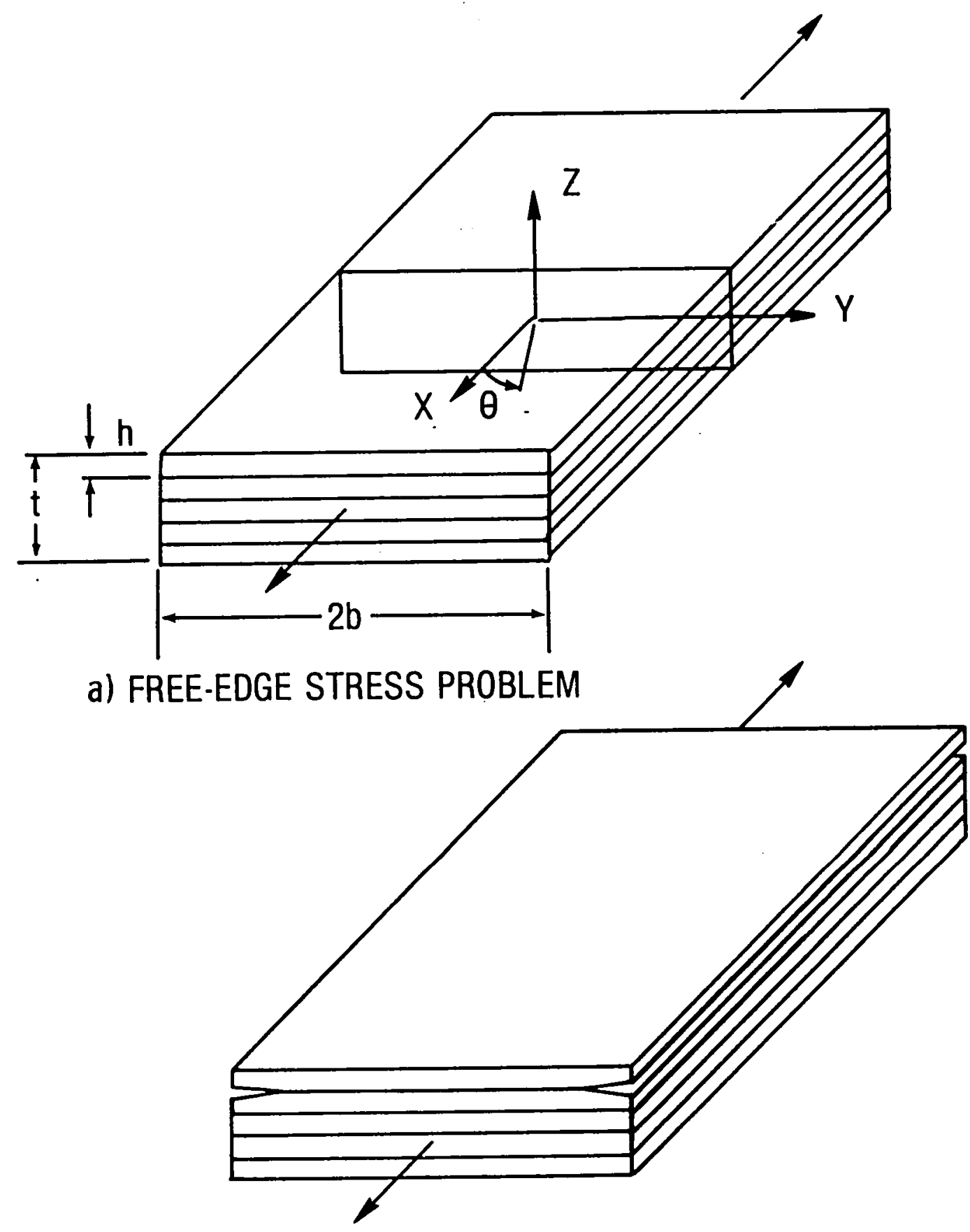

b) EDGE DELAMINATION PROBLEM

Fig. 1--Basic configurations. 


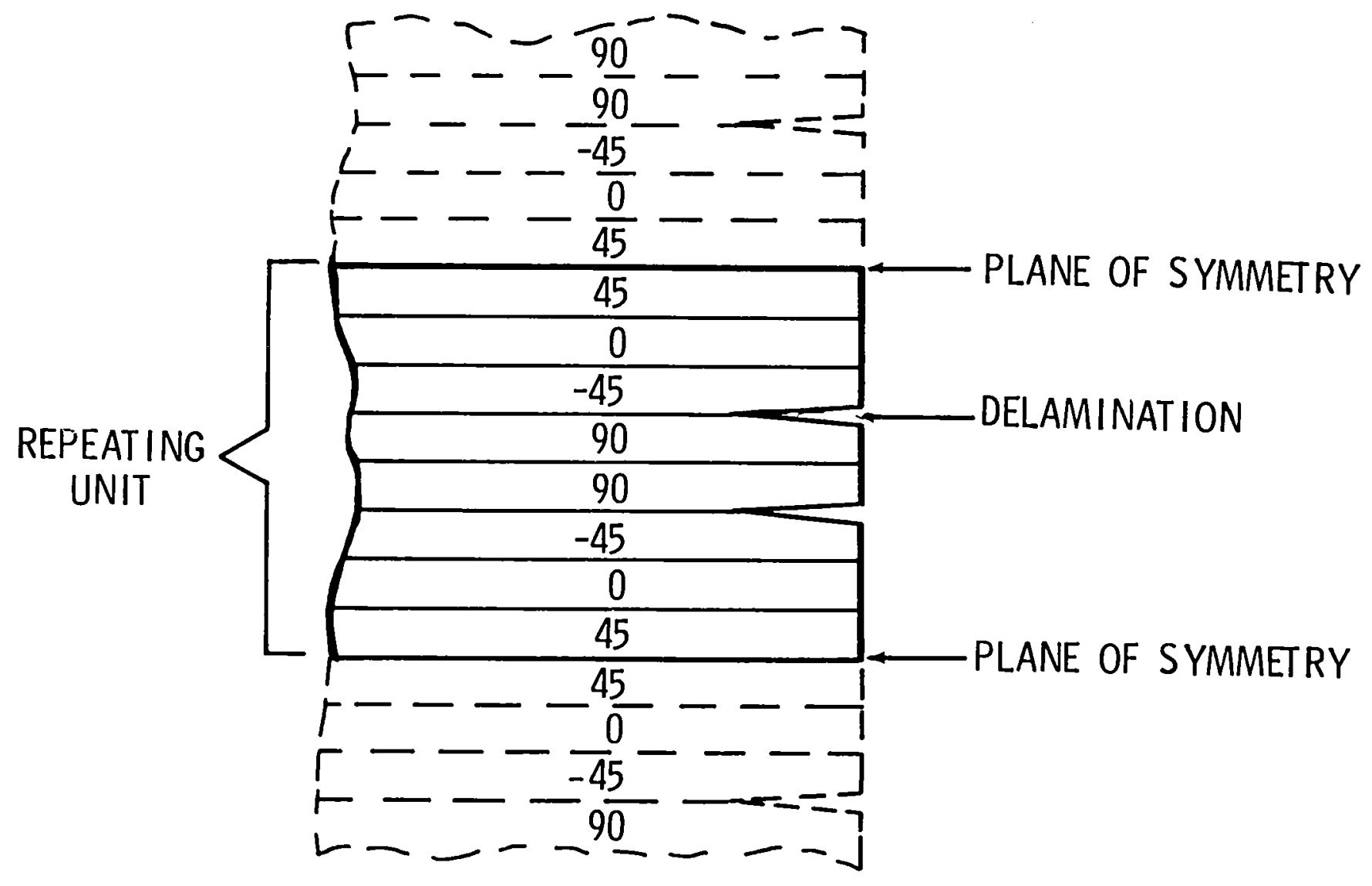

Fig. 2--Schematic of $\left[(45 / 0 /-45 / 90){ }_{s}\right]_{\infty}$ laminate. 


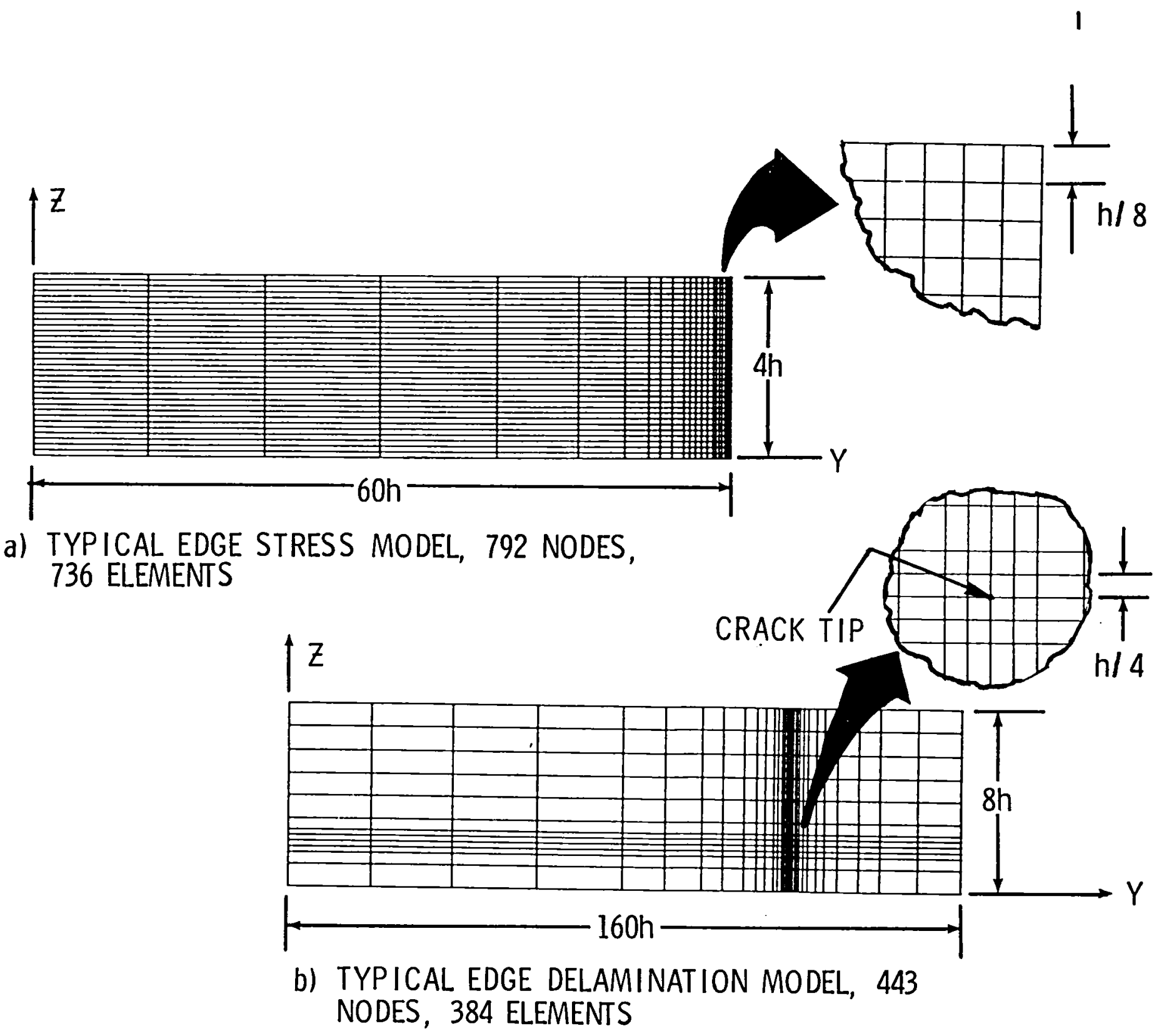

Fig. 3--Typical finite element models. 


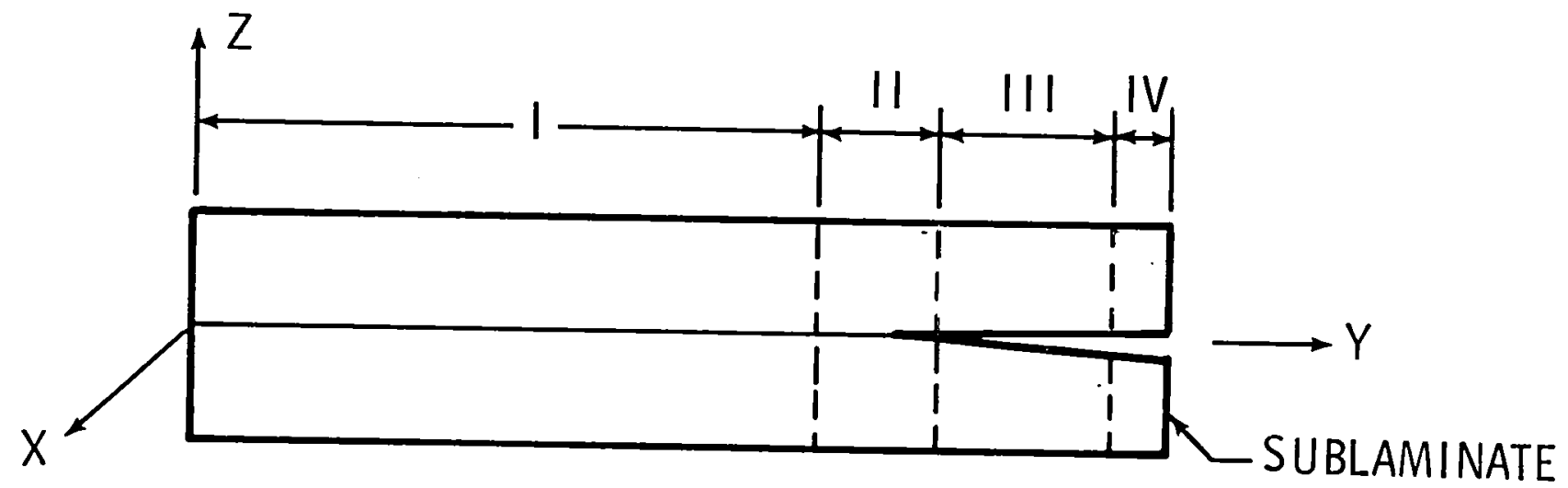

Fig. 4--Laminate divided into four subregions, I - IV. 


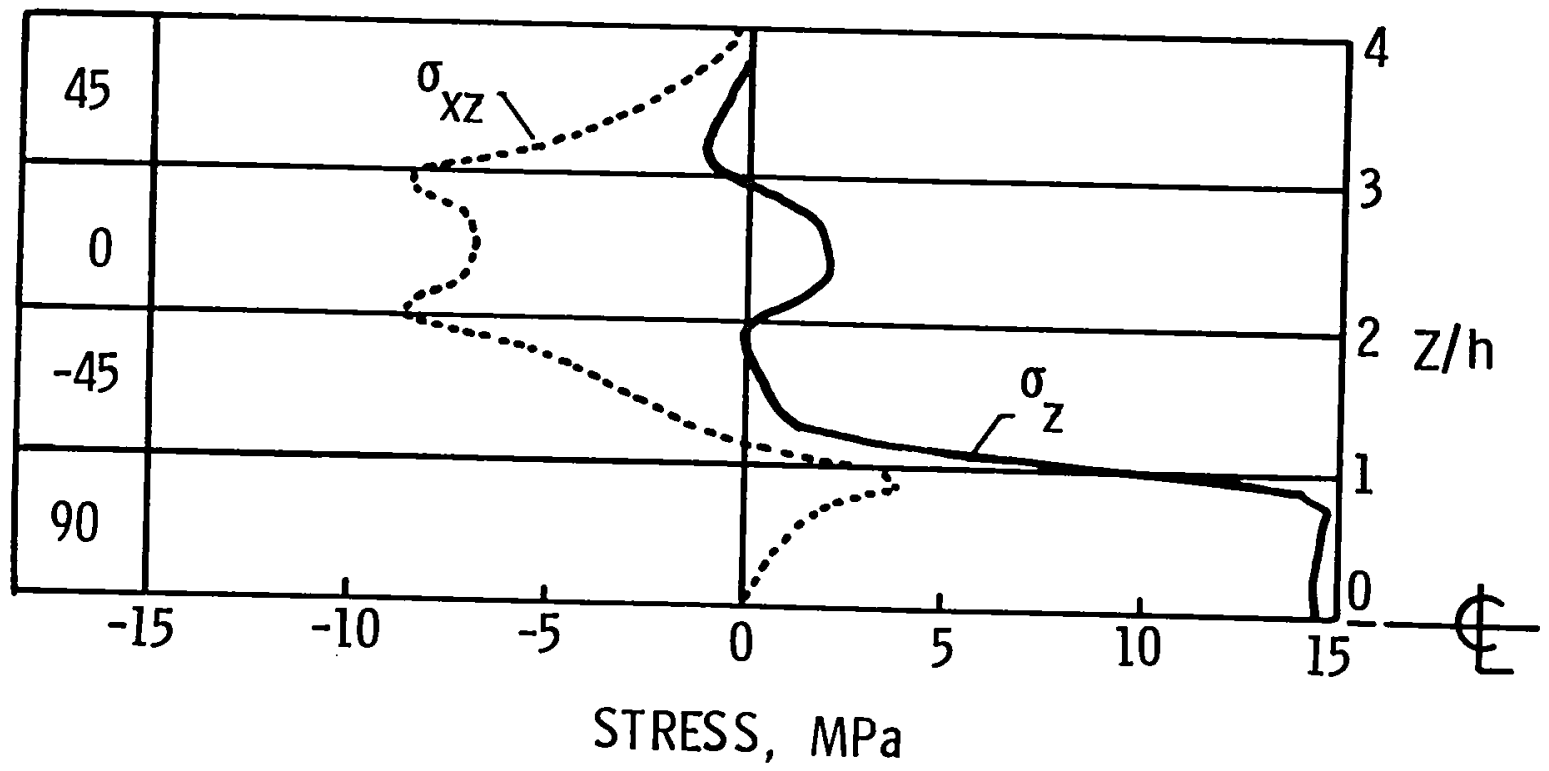

Fig. 5--Distribution of $\sigma_{z}$ and $\sigma_{x z}$ at free edge of [45/0/-45/90] s laminate. $\left(\varepsilon_{0}=0.001\right)$ 


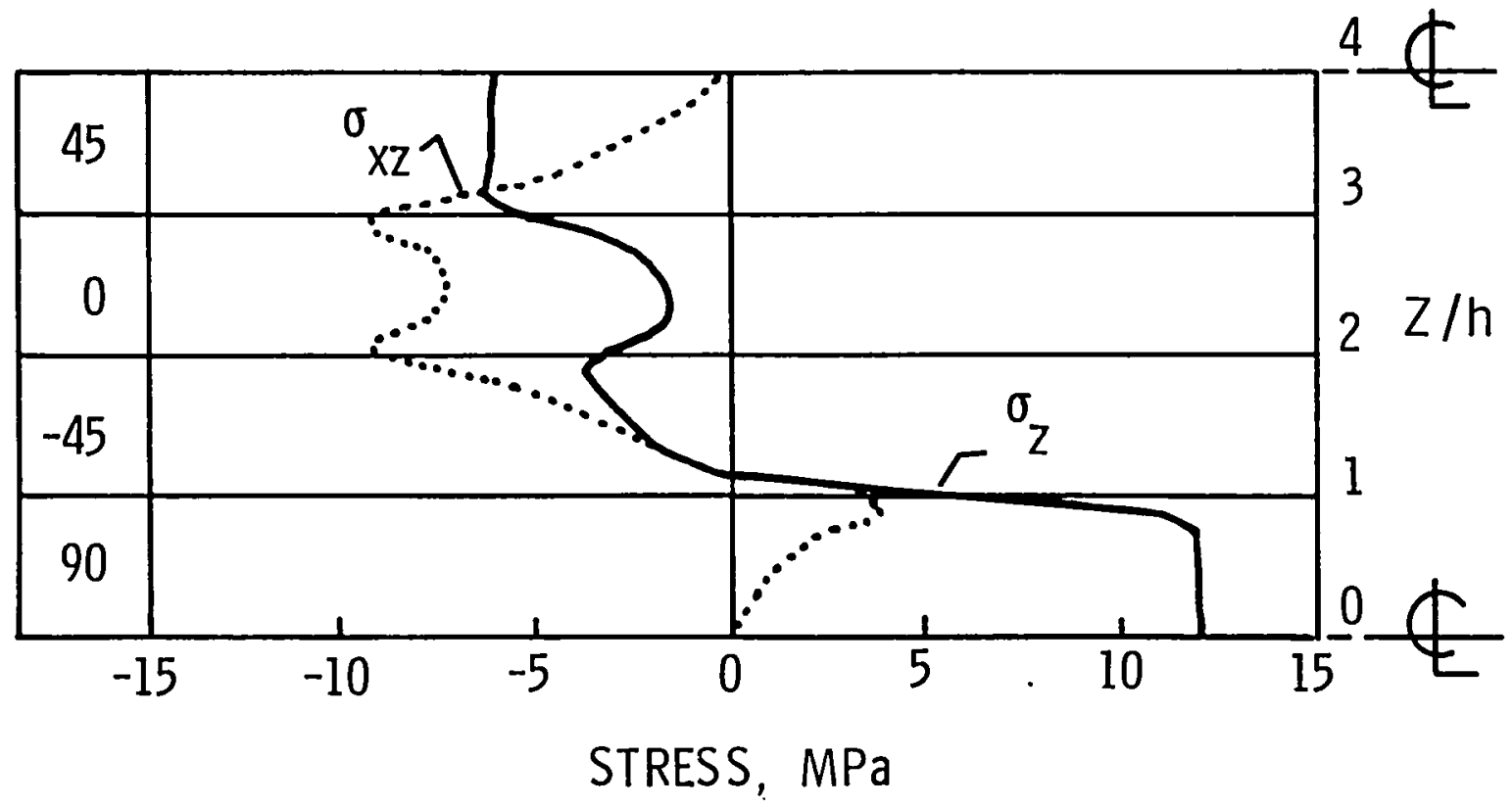

Fig. 6--Distribution of $\sigma_{z}$ and $\sigma_{x z}$ at free edge of $\left[(45 / 0 /-45 / 90)_{s}\right]_{\infty}$ laminate. $\left(\varepsilon_{\mathrm{o}}=0.001\right)$ 


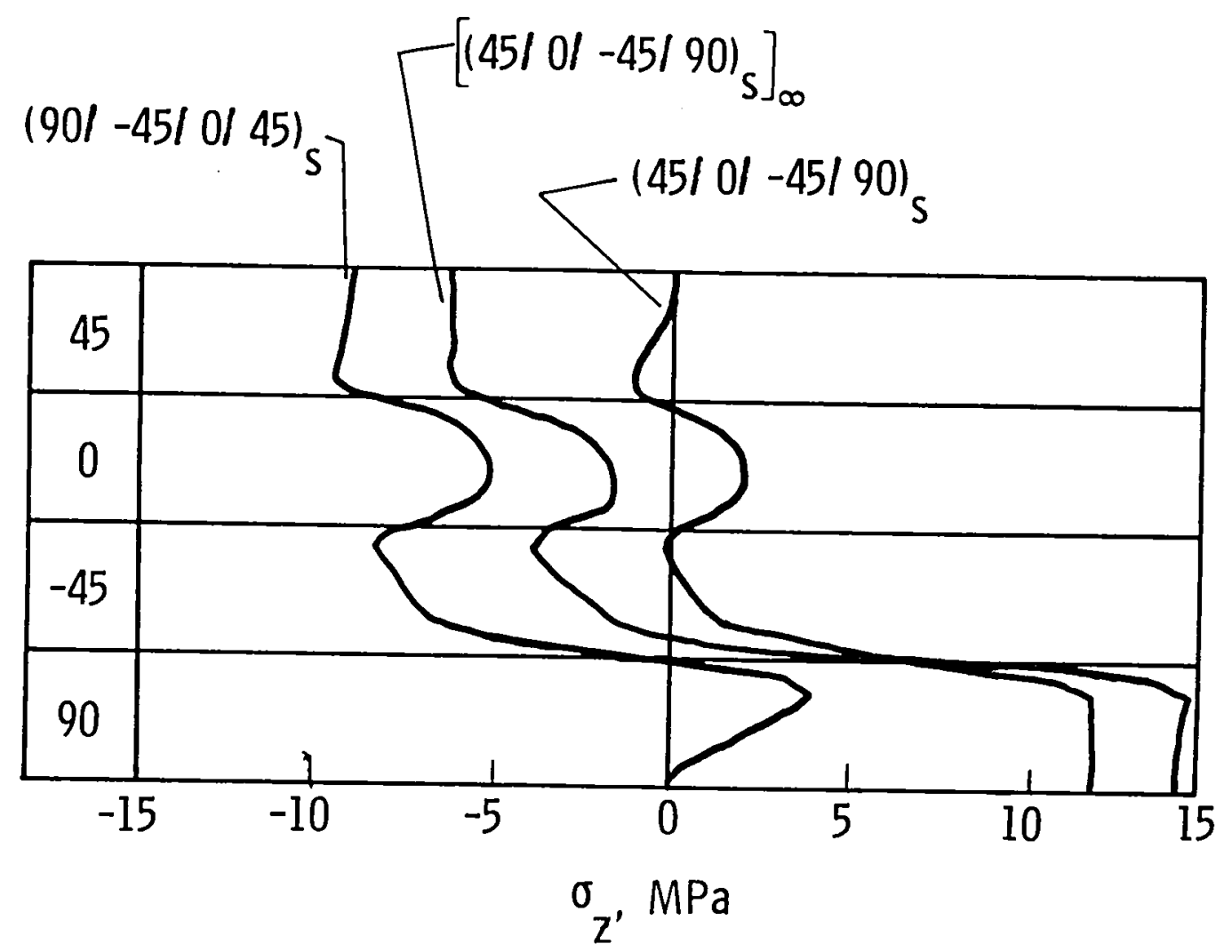

Fig. 7--Distribution of $\sigma_{z}$ at free edge for $[90 /-45 / 0 / 45]_{S}$, [(45/0/-45/90) $]_{\infty}$, and $[45 / 0 /-45 / 90]_{\mathrm{s}}$ laminates. $\left(\varepsilon_{\mathrm{o}}=0.001\right)$ 


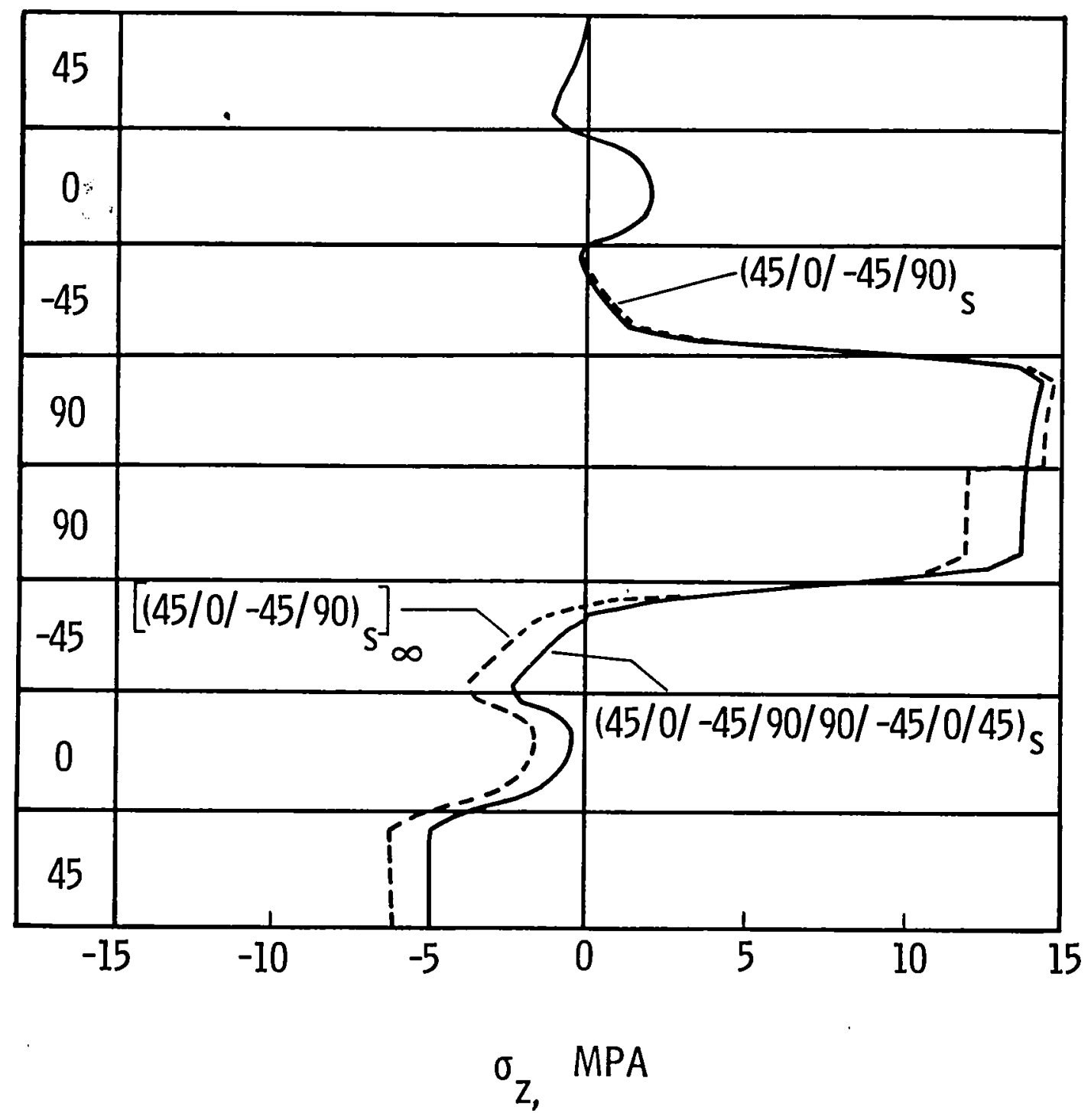

a) $\sigma_{z}$ DISTRIBUTIONS

Fig. 8--Comparison of $\sigma_{z}$ and $\sigma_{x z}$ distributions at free edge for $[45 / 0 /-45 / 90 /$ $90 /-45 / 0 / 45]_{s}$ laminate with those for $[45 / 0 /-45 / 90]_{s}$ and $\left[(45 / 0 /-45 / 90)_{s}\right]_{\infty}$ laminates. $\quad\left(\varepsilon_{0}=0.001\right)$ 


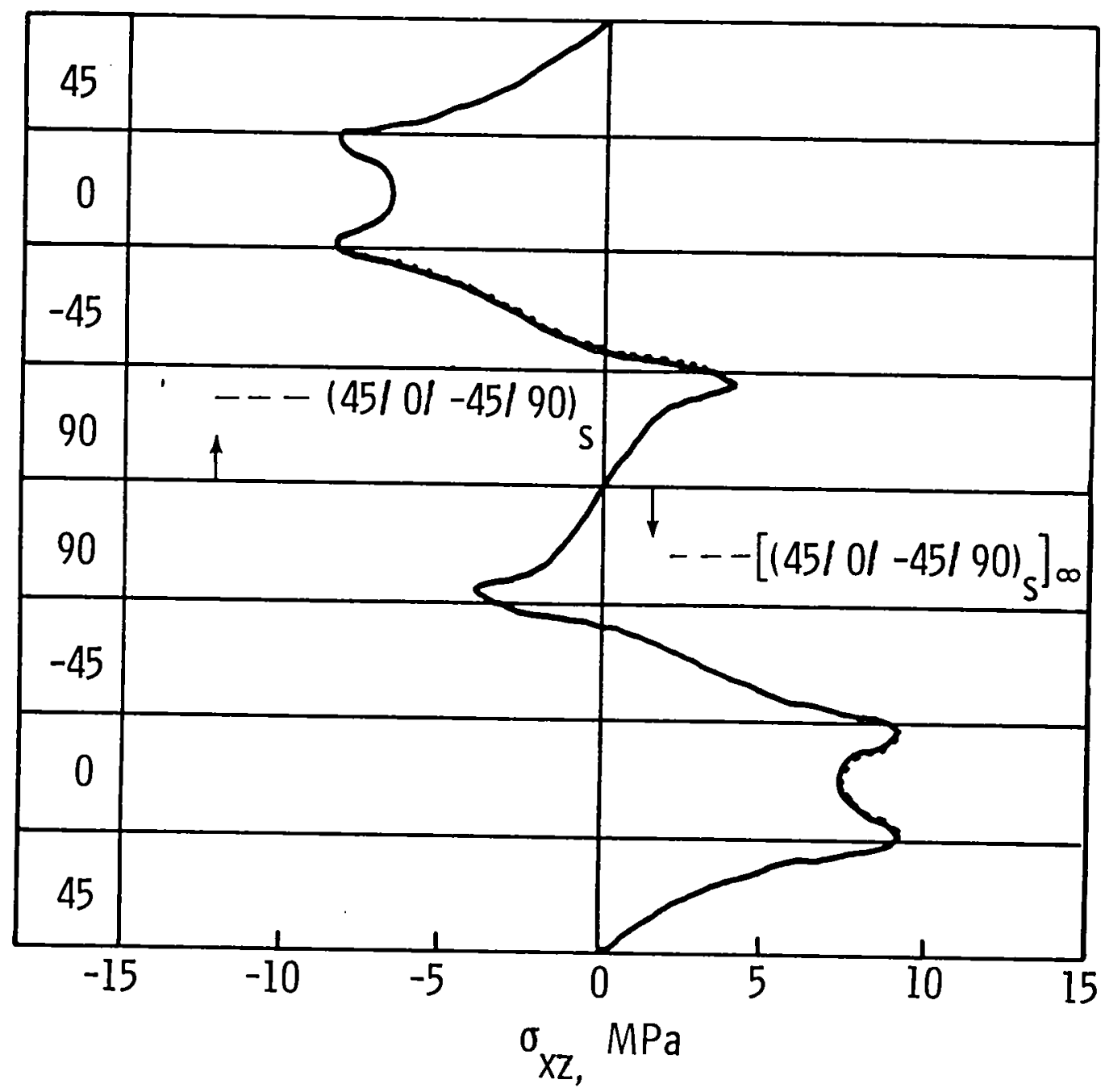

b) $\sigma_{x z}$ DISTRIBUTIONS. SOLID LINE IS FOR (45/ ol -45/ $90 / 90 /-45 / 0 / 45)_{S}$ LAMINATE

Fig. 8--Concluded. 


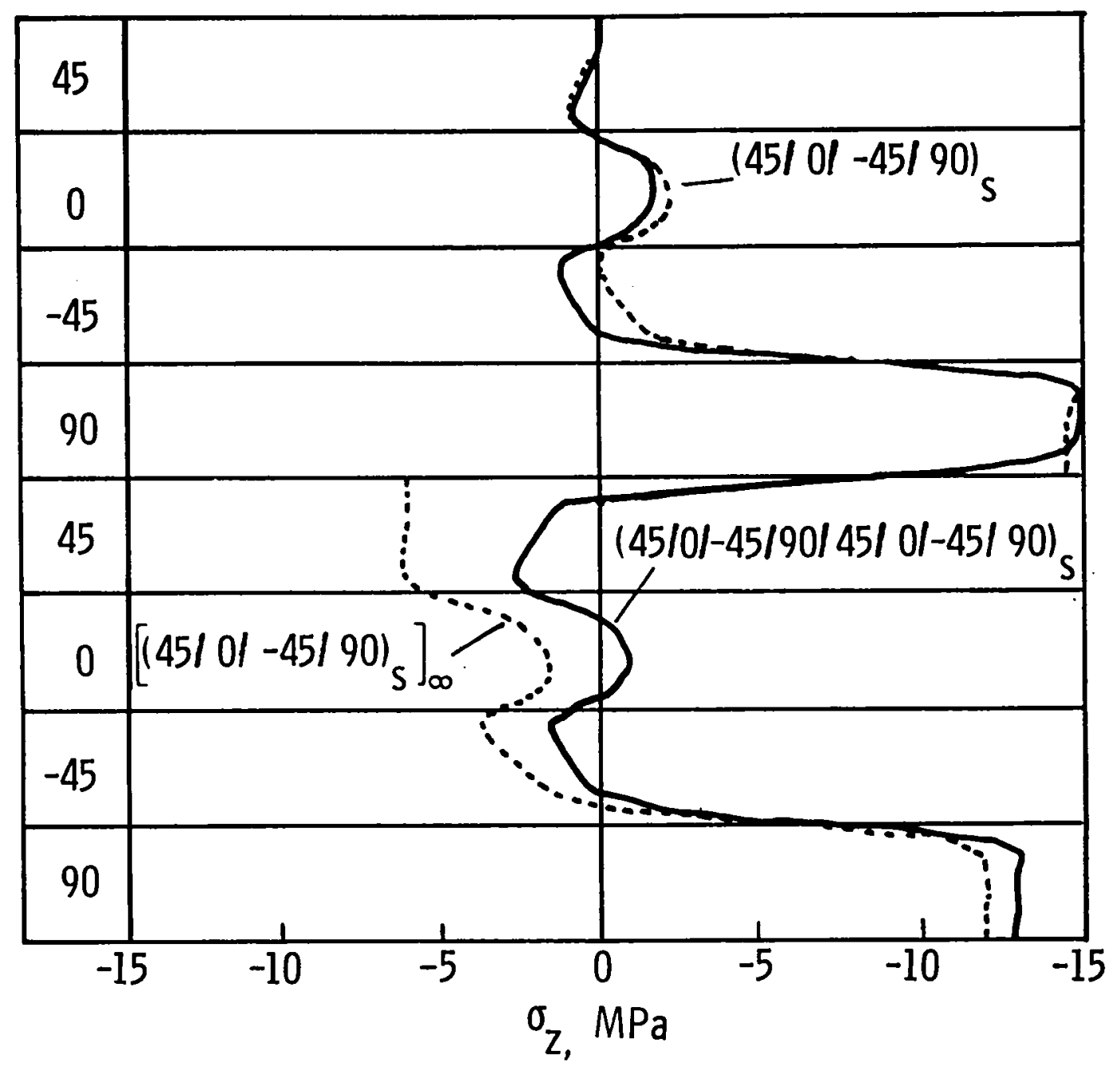

a) $\sigma_{z}$ DISTRIBUTIONS

Fig. 9--Comparison of $\sigma_{z}$ and $\sigma_{x z}$ distributions at free edge for a $[45 / 0 /-45 / 90 /$ $45 / 0 /-45 / 90]_{s}$ laminate with those for $[45 / 0 /-45 / 90]_{s}$ and $\left[(45 / 0 /-45 / 90)_{s}\right]_{\infty}$ laminates. $\left(\varepsilon_{0}=0.001\right)$ 


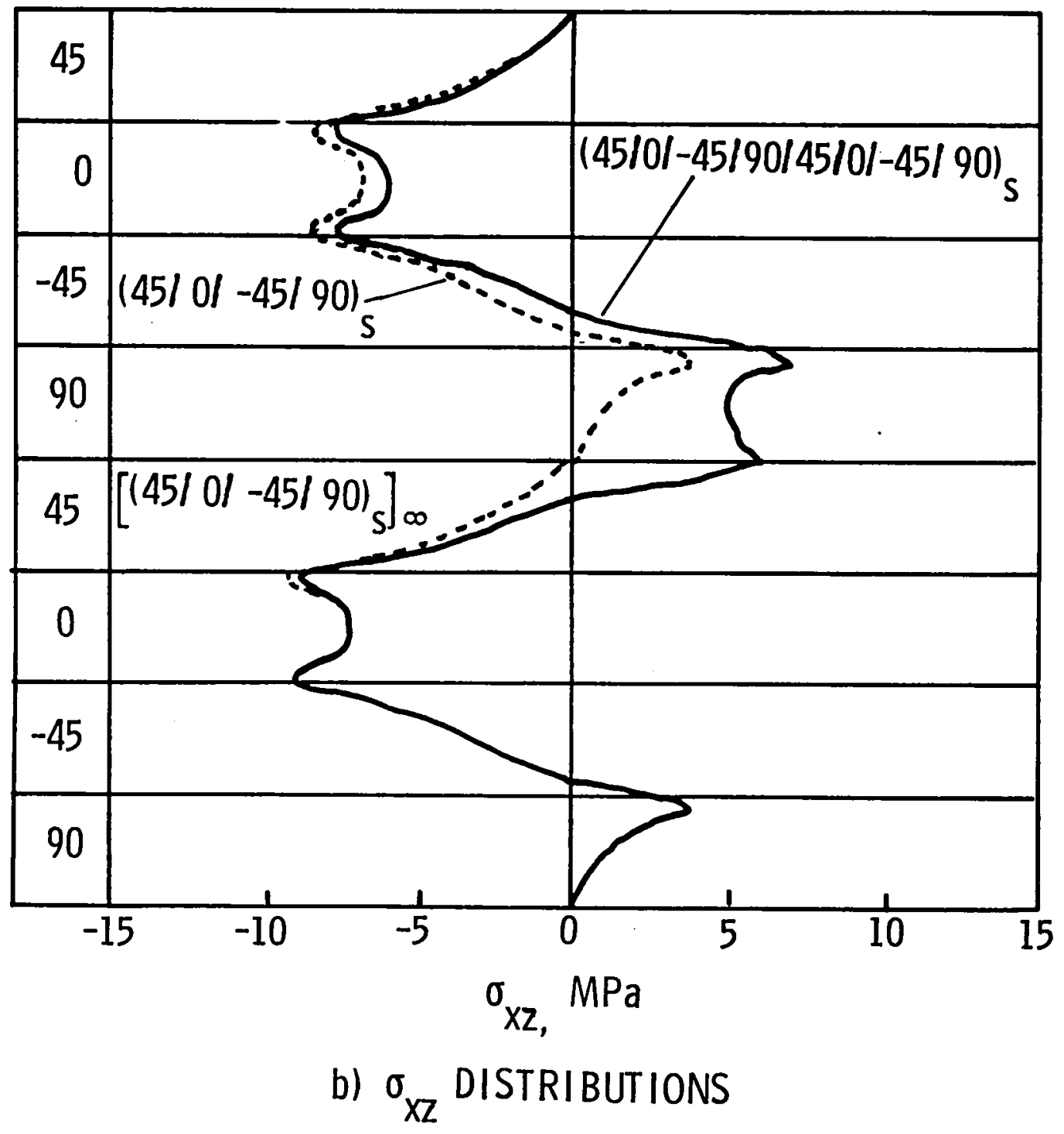

Fig. 9--Concluded. 


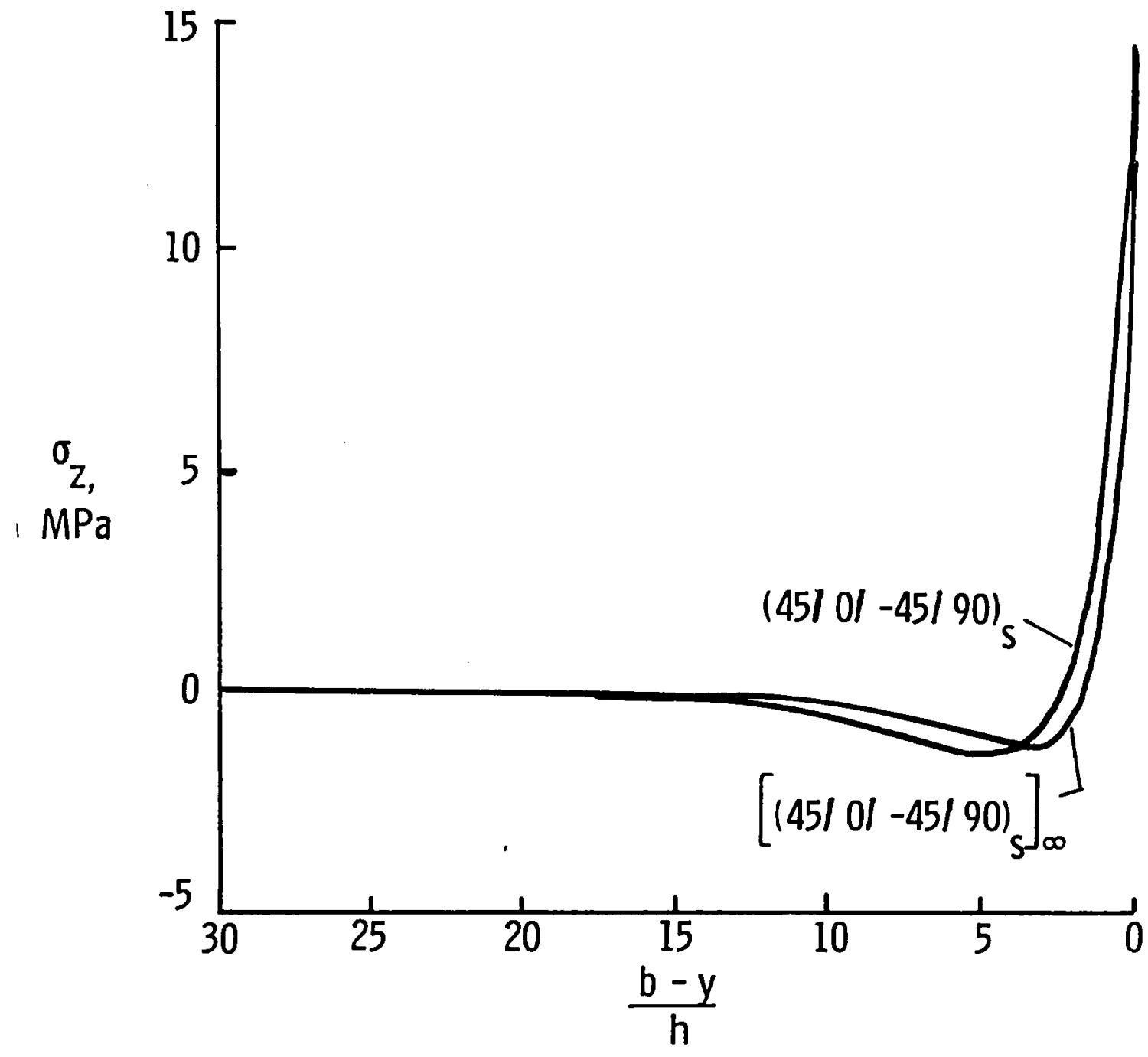

a) 8-PLY AND INFINITELY THICK LAMINATES

Fig. 10--Through-width distribution of $\sigma_{z}$ along 90-90 interface. $\left(\varepsilon_{0}=0.001\right)$ 


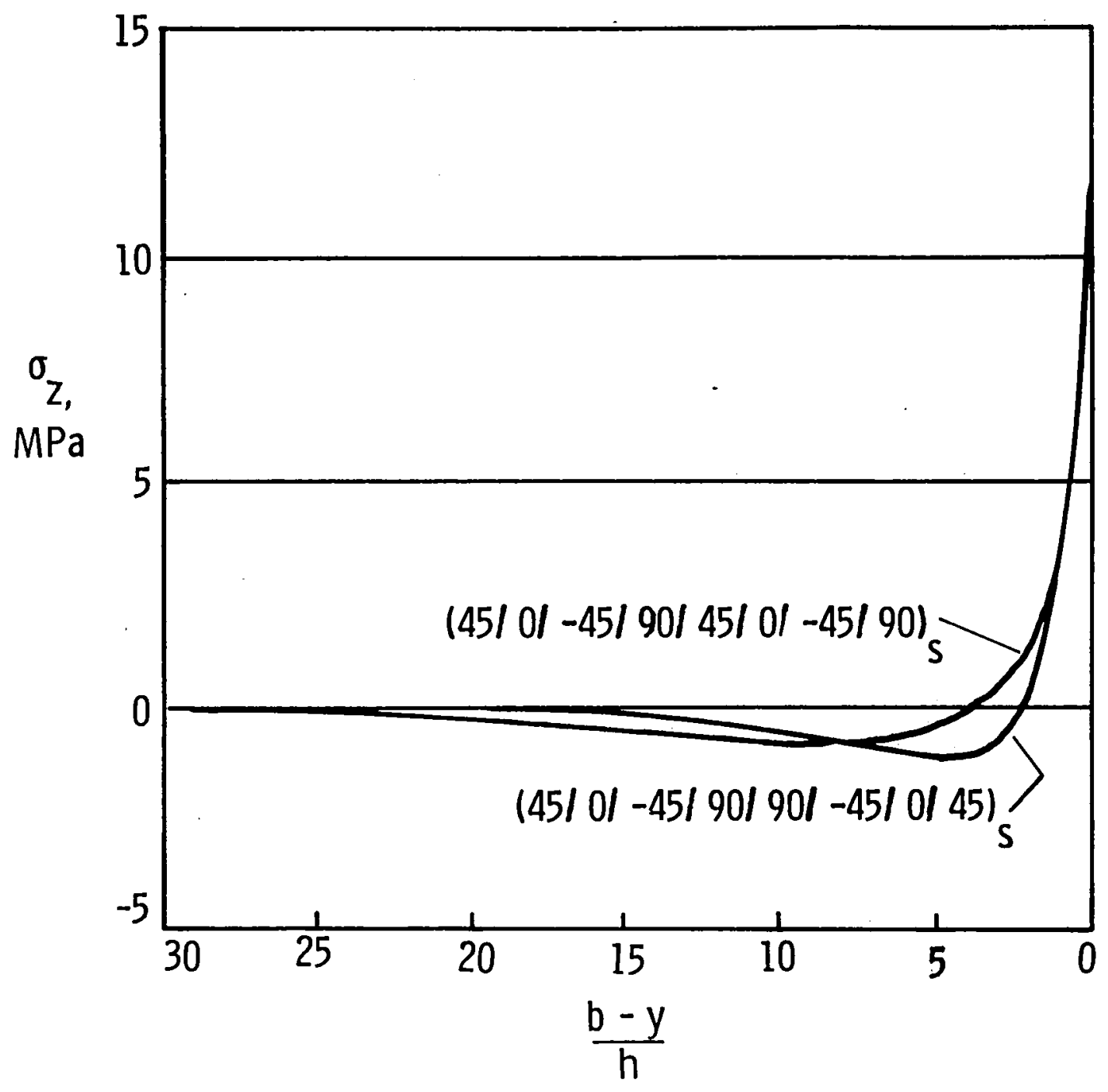

b) LAMINATES WITH 8-PLY AND 16-PLY REPEATING UNIT

Fig. 10--Concluded. 
$\begin{array}{cccc}D & C & B & A \\ \downarrow & \downarrow & \downarrow & \downarrow \\ (45 / 0 /-45 / 90 / 90 /-45 / 0 / 45)\end{array}$

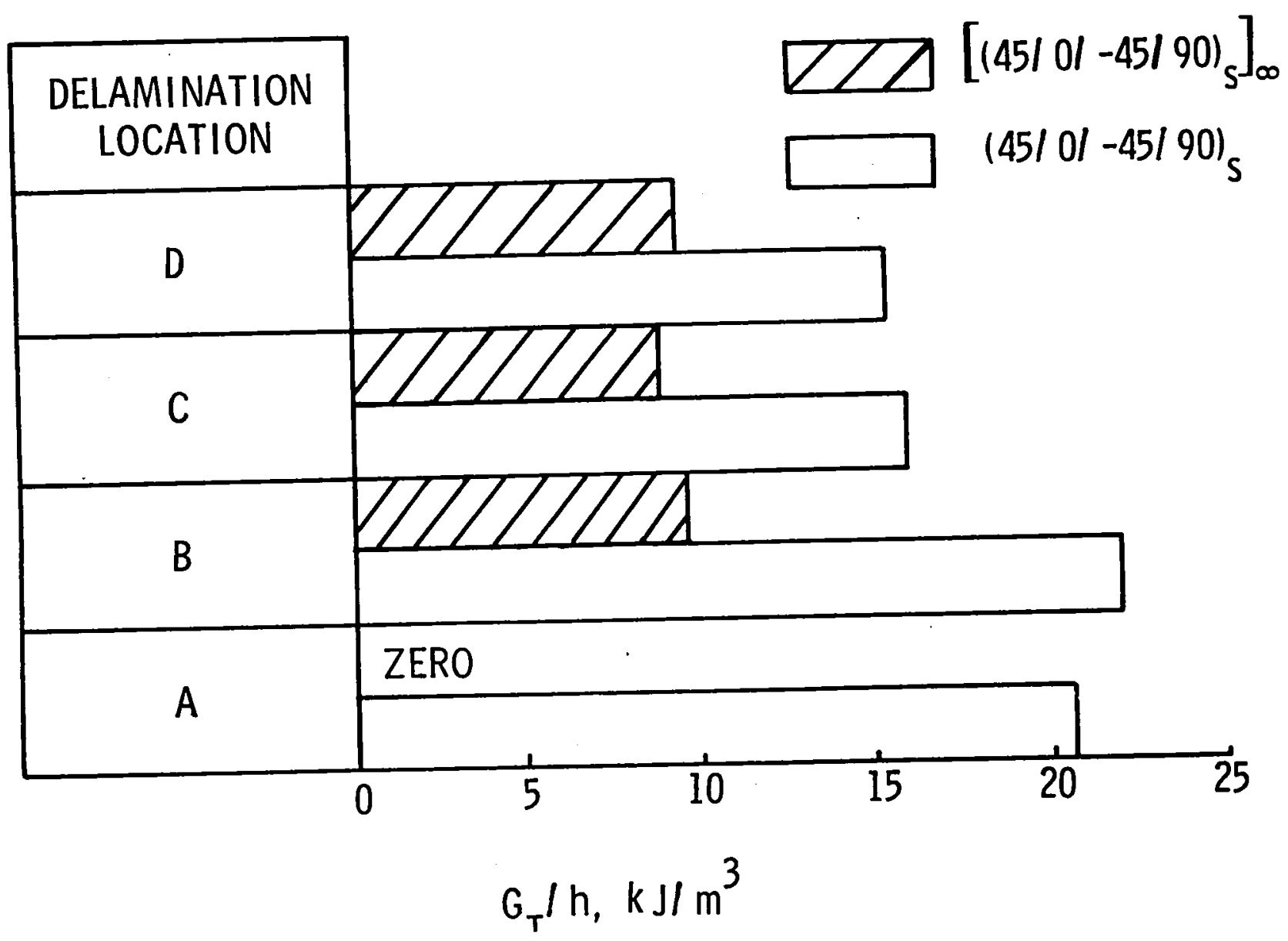

a) SINGLE DELAMINATION

Fig. 11--Total strain-energy-release rate for various delamination locations in $[45 / 0 /-45 / 90]_{s}$ and $\left[(45 / 0 /-45 / 90)_{s}\right]_{\infty}$ laminates. $\left(\varepsilon_{0}=0.001\right)$ 

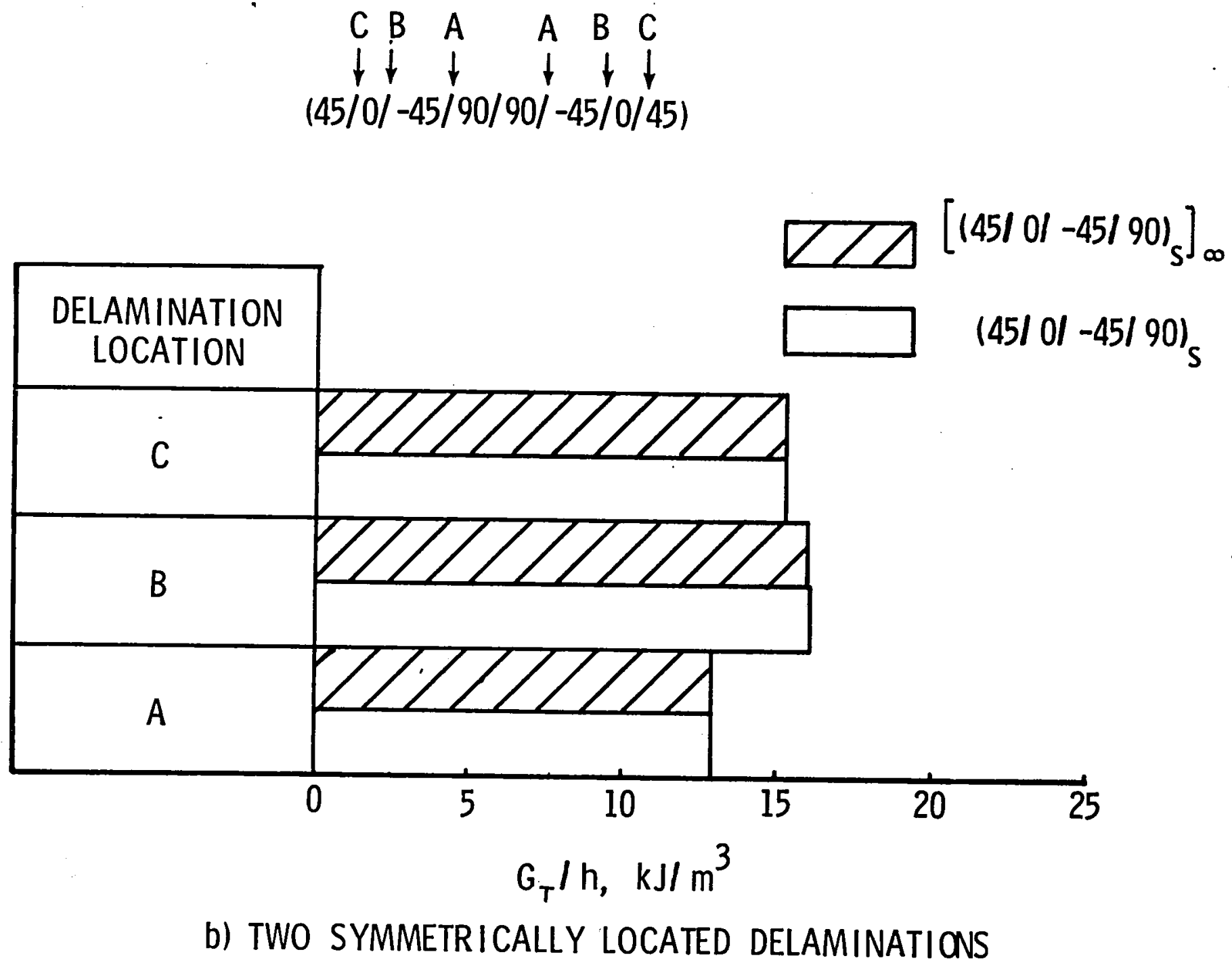

Fig. 11--Concluded. 


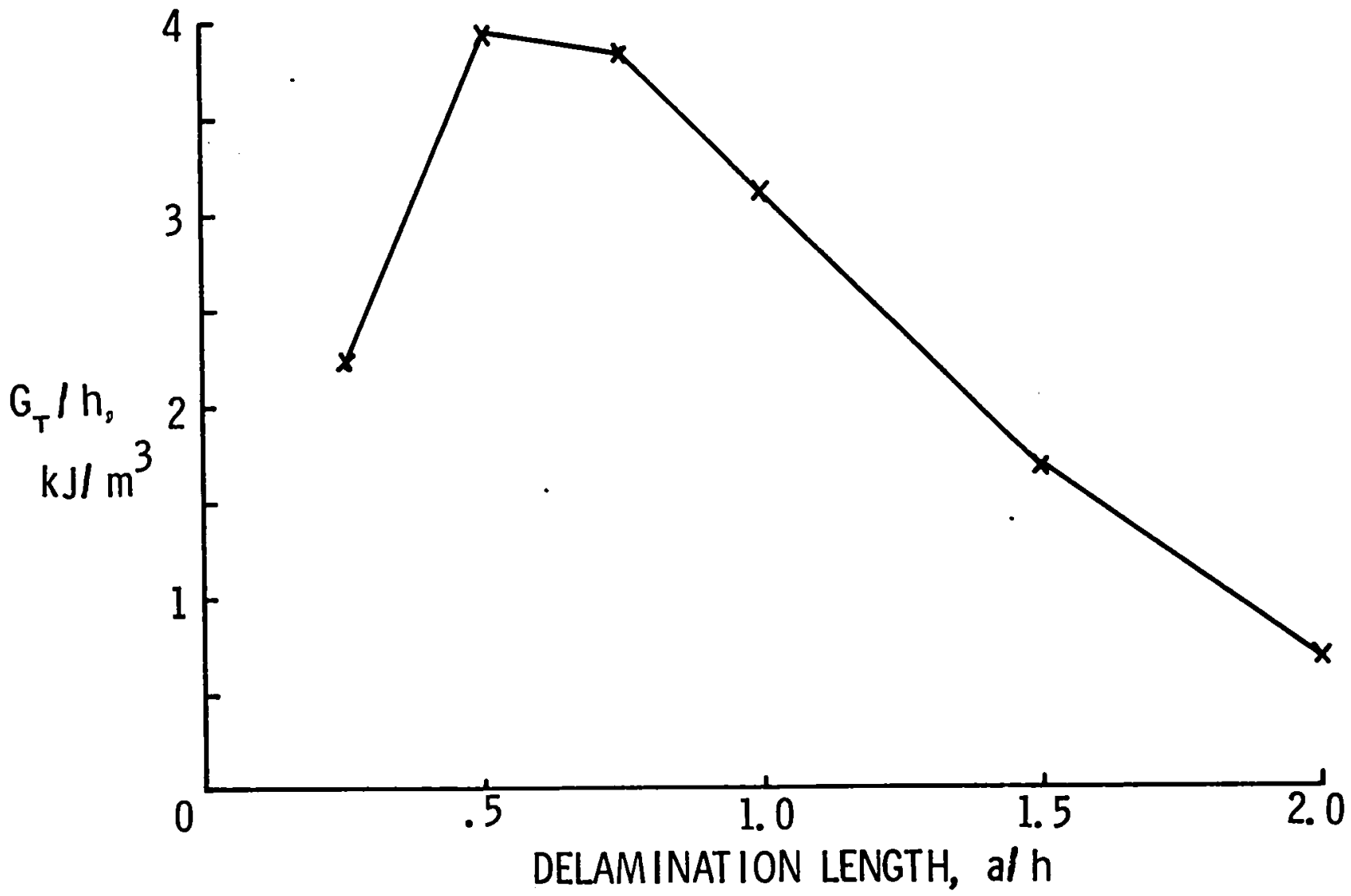

Fig. 12--Variation of strain-energy-release rate with delamination length for a midplane delamination in a $\left[(45 / 0 /-45 / 90)_{s}\right]_{\infty}$ laminate. $\quad\left(\varepsilon_{0}=0.001\right)$ 


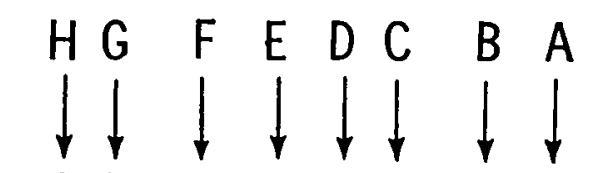

$(45 / 0 /-45 / 90 / 45 / 0 /-45 / 90 / 90 /-45 / 0 / 45 / 90 /-45 / 0 / 45)$

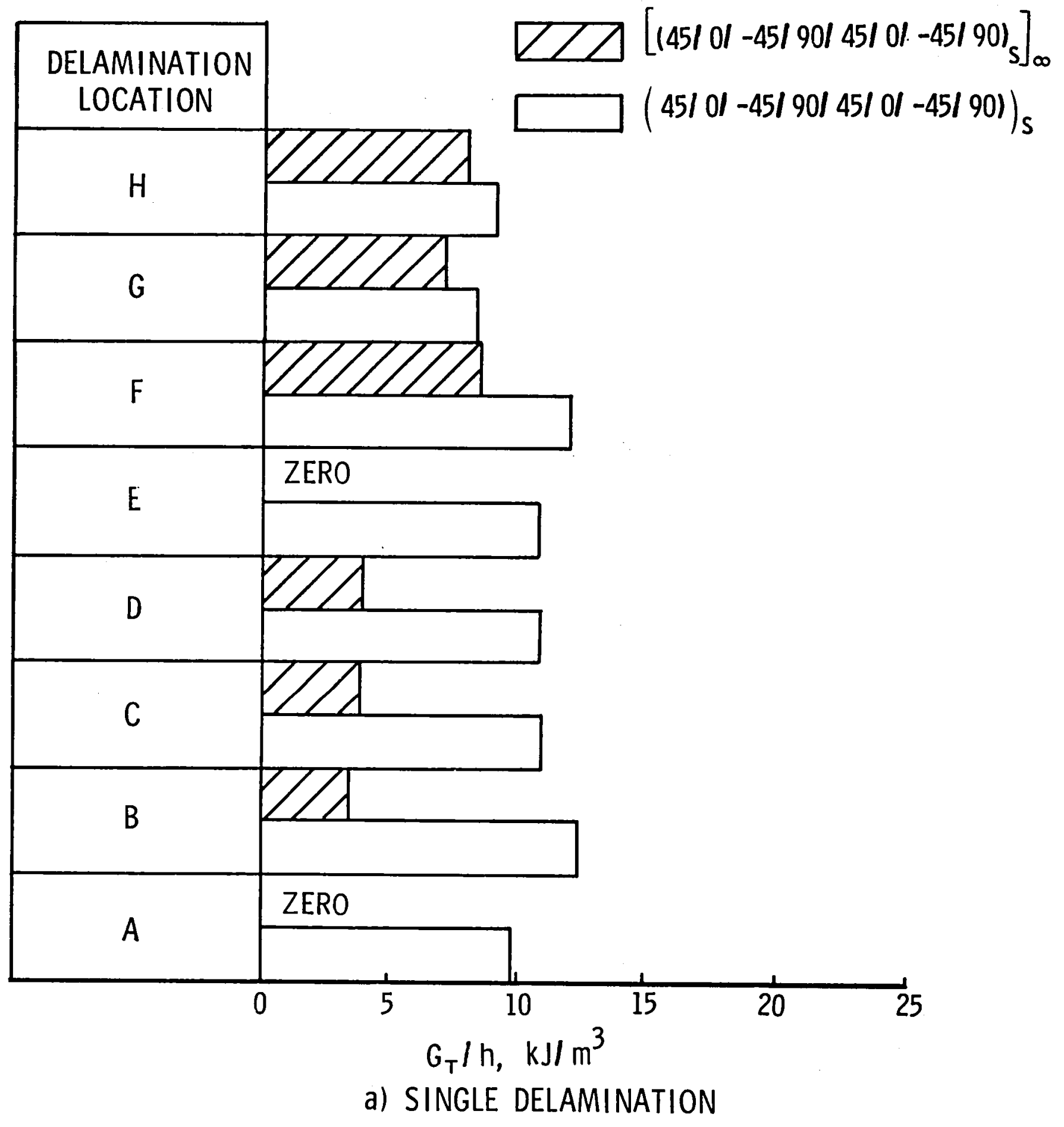

Fig. 13--Total strain-energy-release rate for various delamination locations in $[45 / 0 /-45 / 90 / 45 / 0 /-45 / 90]_{s}$ and $\left[(45 / 0 /-45 / 90 / 45 / 0 /-45 / 90)_{s}\right]_{\infty}$ laminates. $\left(\varepsilon_{0}=0.001\right)$ 


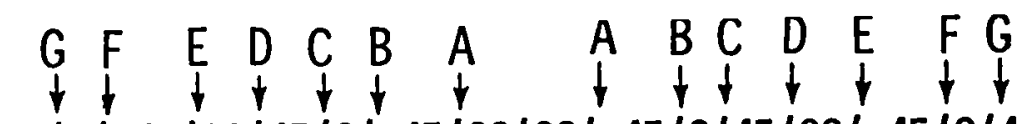

$(45 / 0 /-45 / 90 / 45 / 0 /-45 / 90 / 90 / 45 / 0 / 45 / 90 /-45 / 0 / 45)$

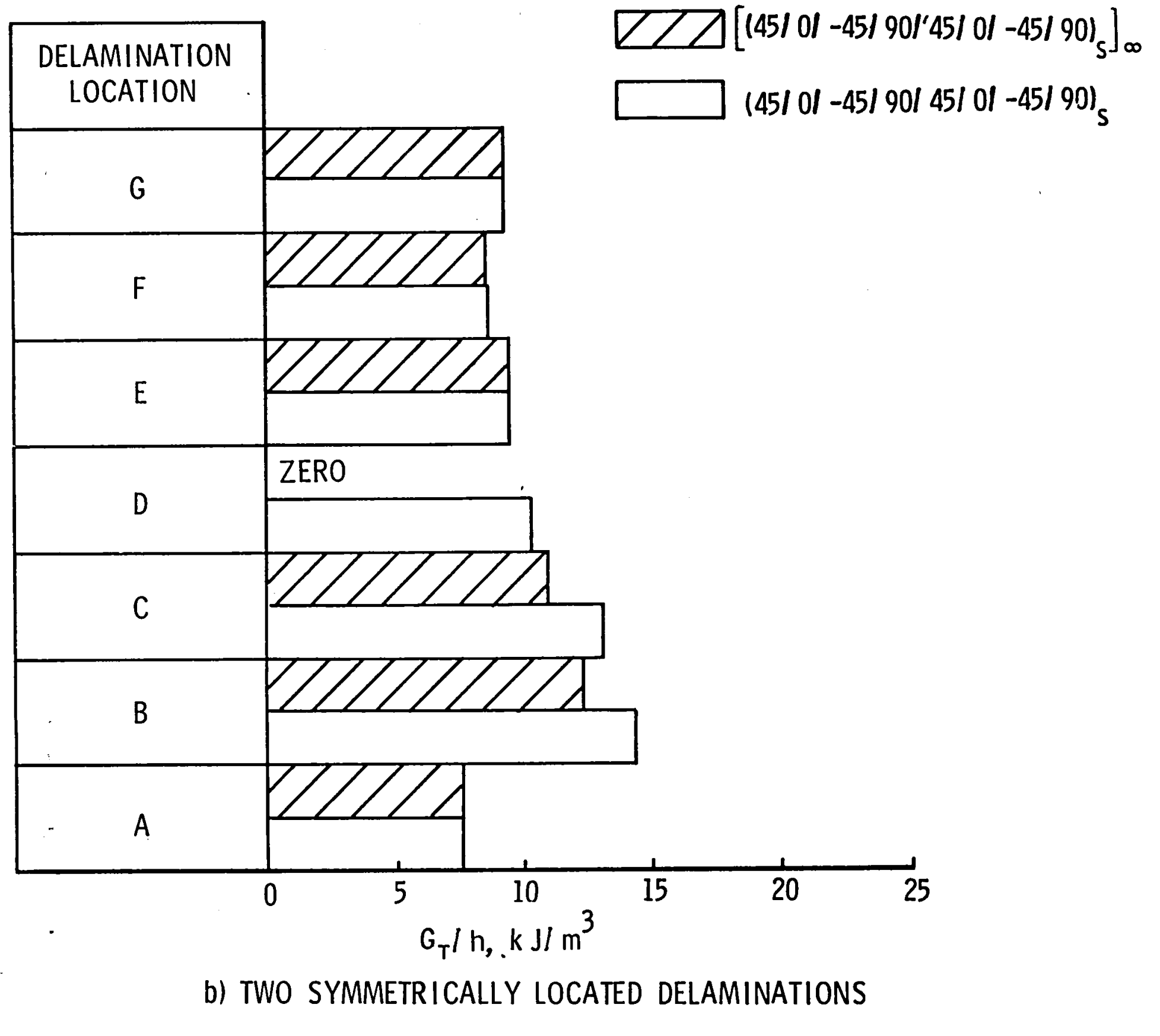

Fig. 13--Concluded. 


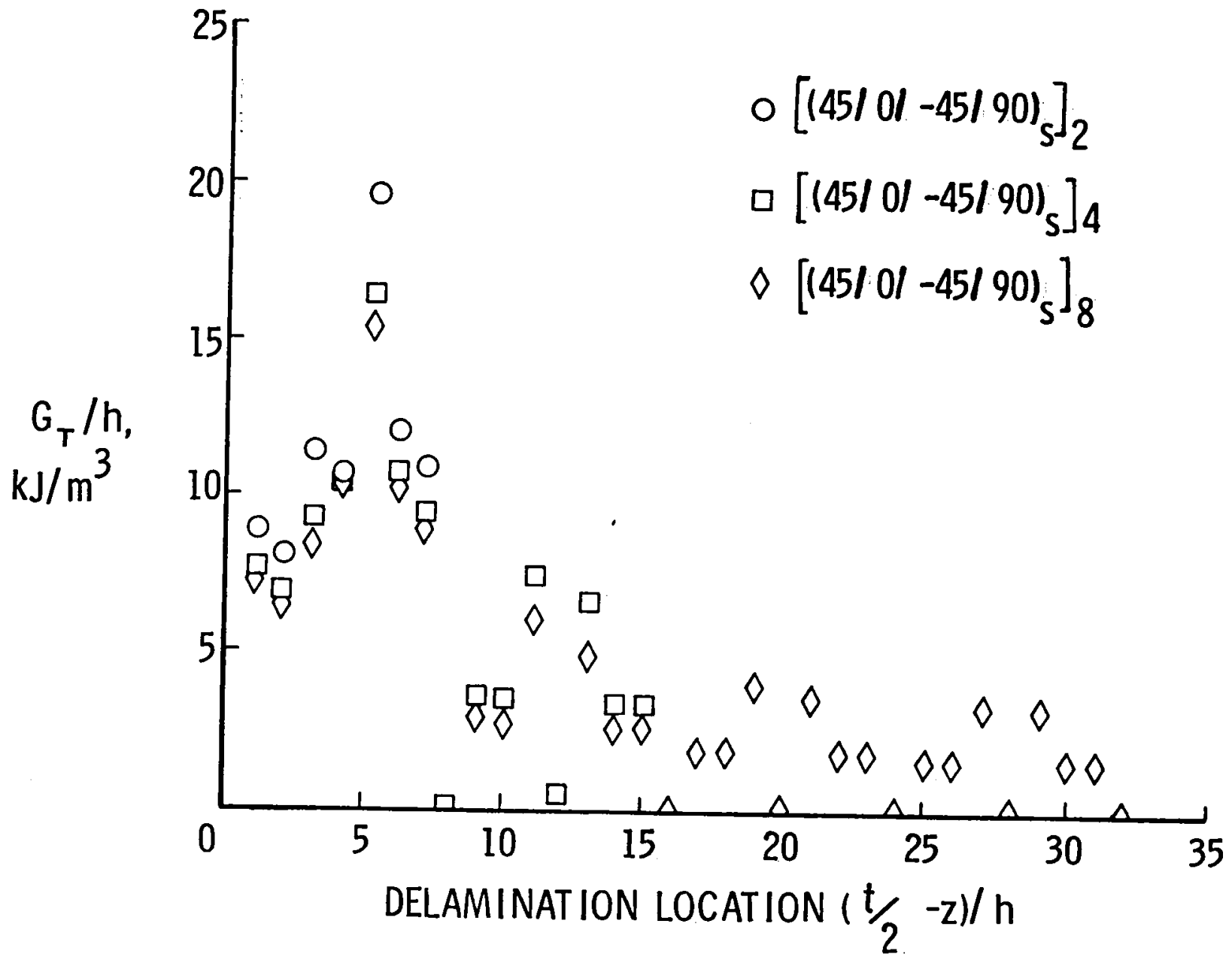

Fig. 14--Total strain-energy-release rate vs. distance of a single delamination from top surface, $(t / 2-z) / h . \quad\left(\varepsilon_{0}=0.001\right)$ 


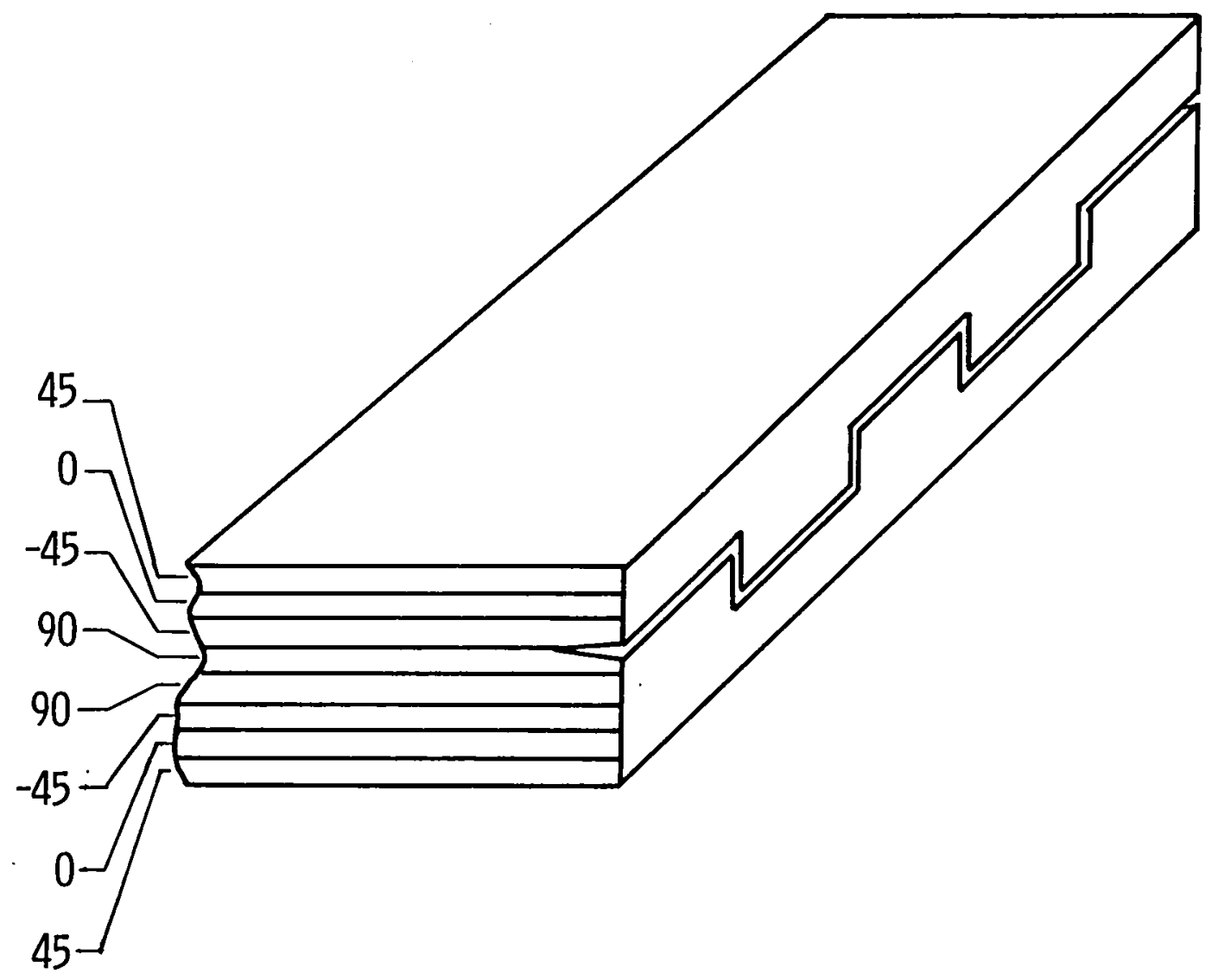

Fig. 15--Delamination growth in a $[45 / 0 /-45 / 90]_{s}$ laminate. 


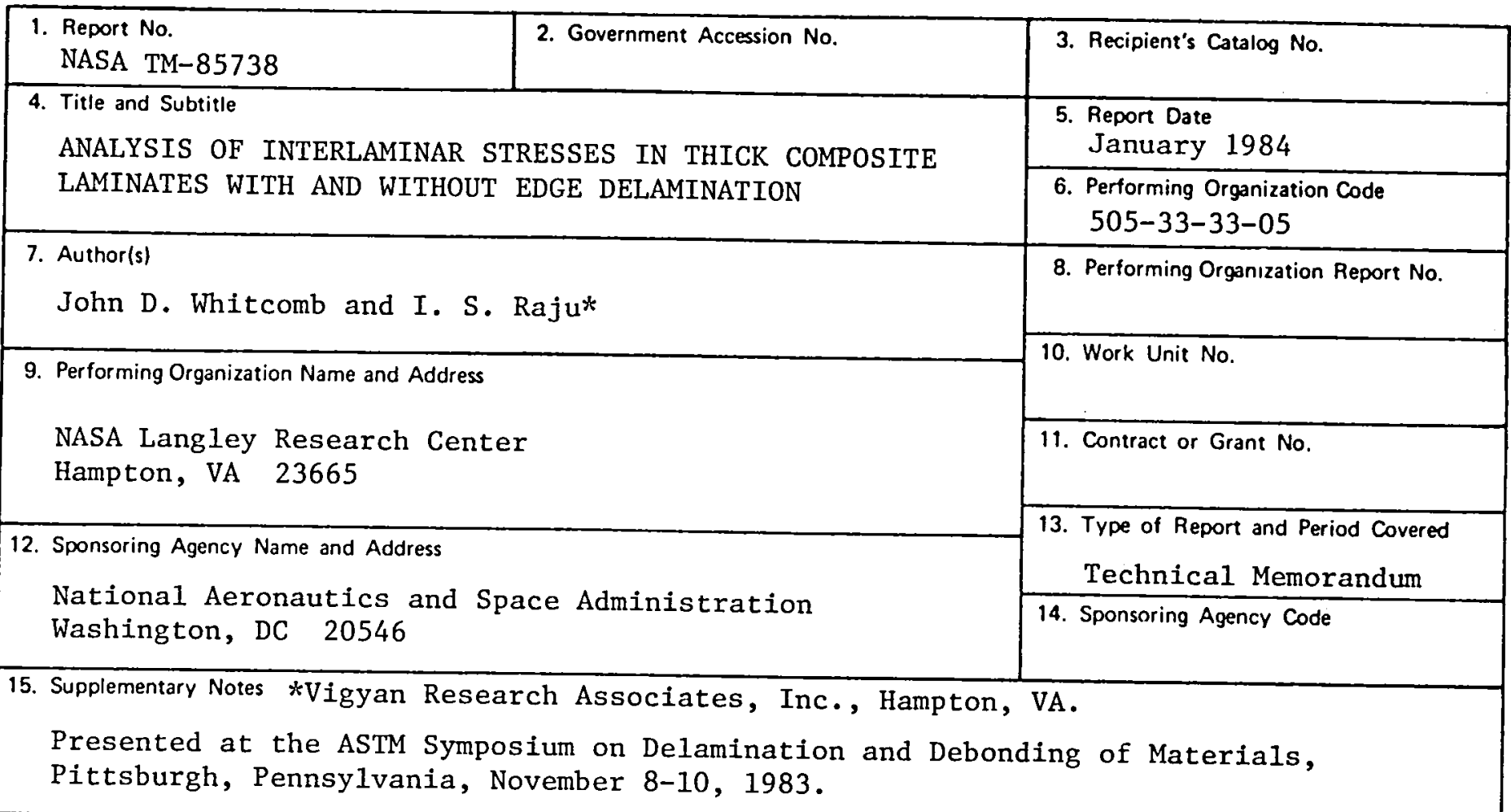

16. Abstract

The effect of laminate thickness on the interlaminar stresses in rectangular quasi-isotropic laminates under uniform axial strain was studied. Laminates from 8-ply to infinitely thick were analyzed. Thick laminates were synthesized by stacking $(45 / 0 /-45 / 90)$ ply groups, rather than grouping like plies. Laminates with and without delaminations were studied.

In laminates without delaminations, the free-edge interlaminar normal stress distribution in the outer ply groups was insensitive to total laminate thickness. The interlaminar normal stress distribution for the interior ply groups was nearly the same as for an infinitely thick laminate. In contrast, the free-edge interlaminar shear stress distribution was nearly the same for inner and outer ply groups and was insensitive to laminate thickness. In laminates with delaminations, those delaminations near the top and bottom surfaces of a thick laminate have much larger total strain-energy-release rates $\left(G_{T}\right)$ and mode $I$-to-total $\left(G_{I} / G_{T}\right)$ ratios than delaminations deep in the interior. Therefore, delaminations can be expected to grow more easily near the surfaces of a laminate than in the interior. This is consistent with experimental results reported in the literature. Also, near surface delaminations in thin laminates tend to have larger strain-energy-release rates than corresponding near surface delaminations in thick laminates.

17. Key Words (Suggested by Author(s)) Composite laminates Interlaminar stresses -Thickness effects Stress analysis Delamination Strain-energy-release rates
18. Distribution Statement

$$
\text { Unclassified - Unlimited }
$$

Subject Category 24
19. Security Classif. (of this report) Unclassified
20. Security Classif. (of this page) Unclassified
21. No. of Pages 48
22. Price" $\mathrm{AO} 3$

${ }^{*}$ For sale by the National Technical Information Service, Springfield, Virginia 22161 



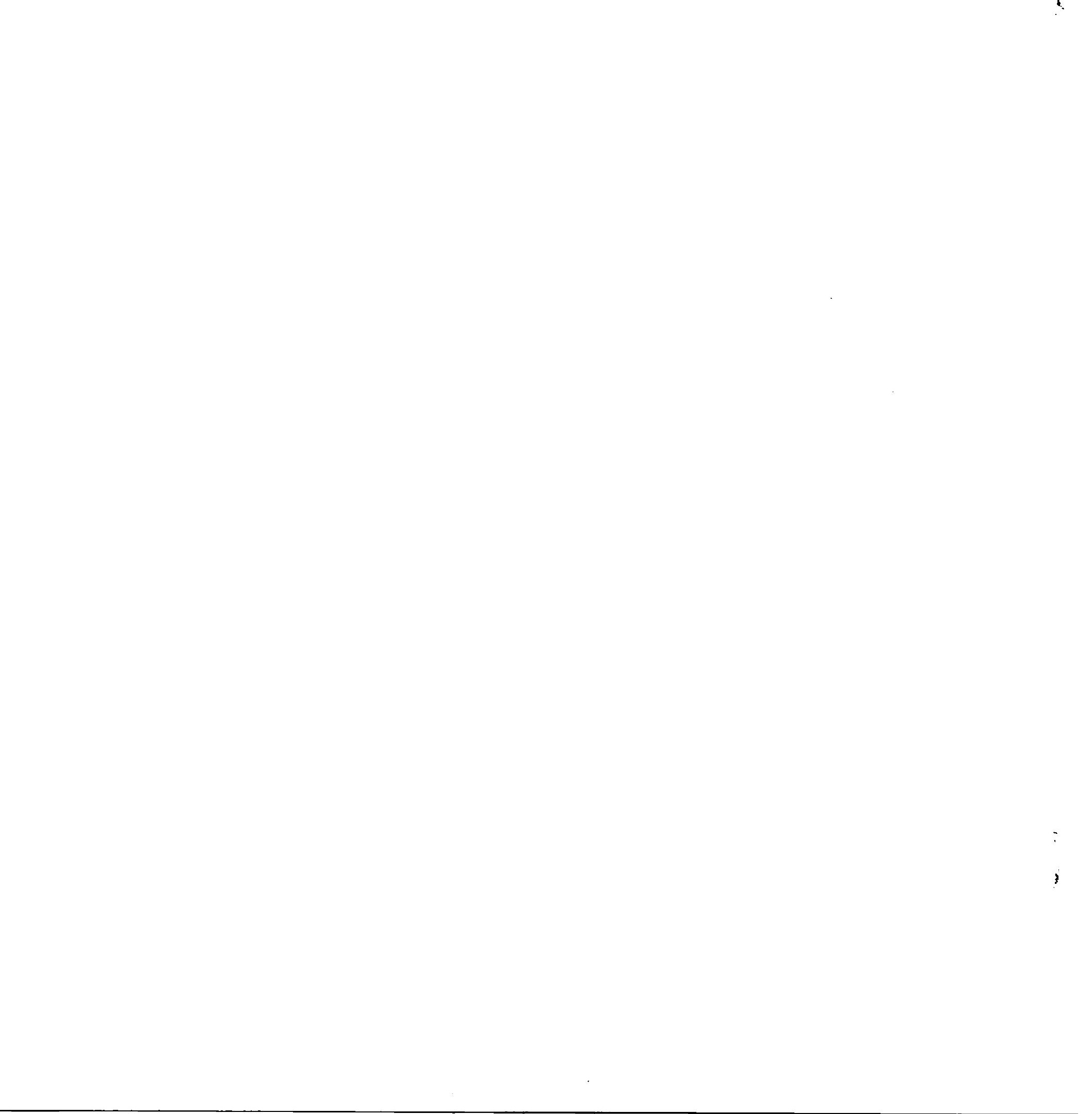

